\title{
Digging out Roots: Pattern Formation, Cell Division, and Morphogenesis in Plants
}

\author{
Ben Scheres and Renze Heidstra \\ Department of Molecular Cell Biology \\ Utrecht University \\ $3584 \mathrm{CH}$ Utrecht, The Netherlands
}

I. Introduction

II. Embryonic Pattern Formation
A. Formation of the Apical-Basal Axis
B. Apical-Basal Pattern Formation
C. Formation of the Radial Axis
D. Radial Pattern Formation

III. Postembryonic Perpetuation of Cellular Pattern
A. Prepatterning of Meristem Cells?
B. What Are the Relevant Prepatterning Cues?

IV. Control of Cell Division during Development
A. Pattern Formation Can Be Uncoupled from Cell Division
B. Cell Fate Specification Can Regulate Cell Division
C. Activation of Meristems
D. Maintaining Meristem Activity

V. Growth and Organ Morphogenesis
A. Growth Can Be Uncoupled from Cell Division
B. Organ Morphogenesis Can Be Uncoupled from Cell Division
C. What Are the Molecules Involved in Determining Organ Size and Shape?

VI. Concluding Remarks

References

\begin{abstract}
The analysis of plant development by genetic, molecular, and surgical approaches has accumulated a large body of data, and yet it remains a challenge to uncover the basic mechanisms that are operating. Early steps of development, when the zygote and its daughter cells organize the embryonic plant, are poorly understood despite considerable efforts toward the identification of relevant genes. Reported cases of genetic redundancy suggest that the difficulty in uncovering patterning genes may reflect overlapping gene activities. Our current knowledge on plant embryo development still leaves open whether mechanisms for axis formation and subsequent pattern formation are fundamentally different in animals and plants. Axis formation may follow the general principle of establishing a peripheral asymmetric cue and mobilizing the cytoskeleton toward this cue-in the case of plants possibly located in the cell wall - but the molecules involved may be entirely different. Embryonic pattern formation involves the establishment of different domains, but although there are
\end{abstract}


candidates, it is not clear whether genes that define these domains are identified yet. Pattern formation continues postembryonically in the meristem, and the flexibility of this process may be explained by a feed-forward system of patterning cues originating from more mature cells. Control of cell division and differentiation, which is important in the meristems - regions of continuous development-has been studied intensively and appears to involve short-range signaling and transmembrane receptor kinase activation. Finally, although high importance of control of cell division rates and planes for plant morphogenesis have been often inferred, recent genetic studies as well as comparative morphological data point to a less decisive role of cell division and to global controls of as yet unknown nature. (1) 1999 Academic Press.

\section{Introduction}

Plants and animals alike develop from a single fertilized egg cell into a multicellular organism with a three-dimensional pattern of specialized cell types. In animals, the route from egg cell to organism can be formally subdivided into distinct steps (Gurdon, 1992), most of which pertain to the gradual emergence of specified regions and cells at appropriate places: (i) Axis formation establishes localized cues. (ii) Cues are interpreted to pattern body regions and tissue and cell types. (iii) Cell fate is progressively determined. (iv) Overt differentiation takes place. Control of cell division operates in parallel with these patterning and specification steps to ensure the appropriate production of new cells.

To identify analogous developmental problems, plant development can be schematized in the same way. Such an exercise does not presuppose similarities at the mechanistic level: several plant-specific features may require novel developmental strategies. For example, individual cells are encased in walls and do not rearrange significantly. The presence of the cell wall may influence the biochemical mechanisms that are available for cell-cell signaling, and the lack of cell movement implies a more significant role for oriented cell division and expansion in development. Furthermore, plant development continues after embryogenesis through the activity of small groups of continuously dividing cells, the meristems. Control of the developmental capacities of these meristems is likely to require special mechanisms.

In the plant sciences, development has been studied for decades by comparative anatomy and surgical experiments, and the plant hormones that modulate development have been a prominent topic of concurrent physiological studies (Steeves and Sussex, 1989). It is, however, only within the past decade that the application of molecular genetic approaches is yielding insights into plant development. For example, the analysis of flower formation has.provided valuable information on the establishment of regional identity in plants. A network of transcription factors involved in floral organ identity has been identified, and new details on their action and regulation continuously emerge (Weigel and Meyerowitz, 1994; Weigel, 
1998). Nevertheless, flower formation is a late event in the development of the multicellular plant, and connections with early patterning events are just beginning to be established (Parcy et al., 1998).

This review aims to provide a perspective on plant development in terms of the formal steps outlined above. To illustrate these steps, we mainly take examples from the development of one anatomically uncomplicated plant organ, the Arabidopsis root. Previous reviews have covered several aspects of root formation, including pattern formation, cell specification, control of cell division, and the execution of cell differentiation and morphogenesis (Dolan and Roberts, 1995a, 1995b; Scheres et al., 1996; Malamy and Benfey, 1997a; Schiefelbein et al., 1997). As root development originates in the embryo, we will include information on embryogenesis where appropriate. Comprehensive reviews on plant embryogenesis have appeared recently (Laux and Jürgens, 1997; Mordhorst et al., 1997), including alternative viewpoints (Kaplan and Cooke, 1997).

\section{Embryonic Pattern Formation}

A short overview of axis formation in plants serves to provide a framework for the discussion on embryo development. Plant embryos contain a primary body axis in the apical-basal dimension and they establish a secondary radial axis (Fig. 1). The embryonic organs, including the root, and two oppositely located groups of stem cells, the meristems, are patterned along the apical-basal axis. The three major tissue types are patterned in the radial dimension. Further (bilateral, dorsoventral) axes emerge later and these will not be discussed here.

\section{A. Formation of the Apical-Basal Axis}

The mechanisms by which the apical-basal axis is specified are hitherto unknown. The multicellular haploid ("gametophytic") phase of the life cycle during which the oocyte and associated cells are formed (Drews et al., 1998) may be relevant for axis specification: the apical-basal axis of the embryo is invariably aligned with the major female gametophyte axis. However, plants can make embryos in the absence of maternal tissue under special circumstances such as tissue culture, implying that axial information can be generated without maternal input. Nevertheless, it is reasonable to propose a role for maternal information in normal axis specification (for further discussion, see Jürgens (1995) and Jürgens et al. (1997)).

There are some clues on how the main axis may become fixed. In the brown alga Fucus, with early embryo development reminiscent of that of higher plants, the primary axis is established by external cues, and axis fixation is dependent on the cell wall (Kropf et al., 1988). Targeted secretion is required for cell wall polariza- 

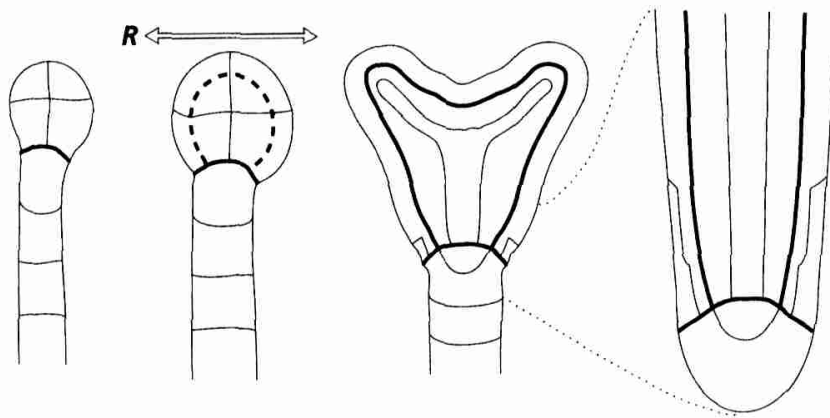

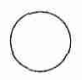

A

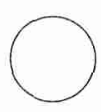

B

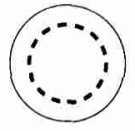

C

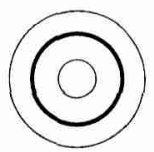

D

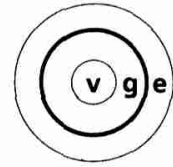

E

Fig. 1 Axis formation and the formation of the main tissues in plant embryogenesis. The first asymmetric cell divisions that manifest apical-basal and radial polarity are shown in Arabidopsis embryos of successive stages and in the postembryonic root. A, first division of zygote; B, octant stage; C, 16cell stage; D, heart stage; E, seedling root. Upper row, longitudinal view; lower row, transverse view. $A$, apical; $B$, basal; $R$, radial. v, vascular tissue; $g$, ground tissue e, epidermal tissue.

tion, and the polarized wall orients the first division plane of the zygote (Shaw and Quatrano, 1996). In analogy, the GNOM gene is required to position the zygotic division plane in Arabidopsis (Mayer et al., 1993) and, using expression of an early apical marker gene as a criterion, also for fixation of the apical-basal axis (Vroemen et al., 1996). The GNOM protein shares homology with yeast guanine nucleotide exchange proteins involved in vesicle transport (Shevell et al., 1994; Bush et al., 1996; Peyroche et al., 1996; Mossessova et al., 1998). This may suggest that targeted secretion to the cell wall plays a role in axis fixation in plants as it does in Fucus, although the large evolutionary distance and the differences in habitat between vascular plants and algae argue against an overly optimistic view on shared mechanisms.

Which cues are established during axis specification to initiate pattern formation in higher plants? Laser ablation studies in Fucus again implicate the cell wall. Zygotic daughter cells can switch fate if they are manipulated to contact a different cell wall (Berger et al., 1994). Therefore the wall has a capacity to instruct cell fate, in addition to its role in orienting the zygotic division plane. It remains to be investigated whether localized patterning cues similarly reside in the cell wall of higher plant zygotes. Notably, the asymmetric segregation of cell fate determinants and concomitant control of cell division plane also take place in yeast, nematodes, and flies (Yan and Yan, 1998). 


\section{B. Apical-Basal Pattern Formation}

Whatever the cues may be that initiate apical-basal pattern formation, in many plant species asymmetry is immediately evident when the first embryonic cell division generates a large basal cell and a small apical cell with different destinies (Fig. 2A). In Arabidopsis, embryogenesis has been described extensively (Mansfield and Briarty, 1991; Jürgens and Mayer, 1994). The basal cell will form the extraembryonic suspensor and the hypophysis that will become part of the embryo proper (Figs. 2B and 2C). The apical cell will give rise to the remainder of the embryo. Although twin (twn) mutants can give rise to basal cell-derived embryos (Vernon and Meinke, 1994; Zhang and Sommerville, 1997), demonstrating that the basal cell retains the capacity to adopt apical fates, the corresponding genes do not specify cell fates. For example, the molecular lesion in $t w n 2$ causes altered expression of a valyl-tRNA-synthase gene and apical cell progeny arrests, followed by the development of embryos from the basal cell. It is postulated that the apical cell suppresses the alternative fate of the basal cell in wild-type embryos and that apical cell defects in the twn mutants obliterate this control (Vernon and Meinke, 1994).

The embryo proper divides into apical, central, and basal domains with stereotyped cell division patterns (Fig. 2C; Mayer et al., 1991). Subsequently, the embryo is partitioned in regions that will give rise to the seedling shoot apical meristem, embryonic leaves (cotyledons), hypocotyl, root, and root apical meristem (Figs. 2D and 2E). The prospective organ primordia do not correlate with the three early domains, showing that the final definition of organs and the positioning of organ boundaries are later events (Scheres et al., 1994). The root, for example, derives from cell groups that have been separated from the first zygotic division onward (Fig. 2). The first region, encompassing most of the root, derives from the central domain and consists of concentric layers of the main tissue types (Fig. 1E). A small second region, located distally, derives from the basal domainthe hypophysis - and contains two unique cell types. A second, even more conspicuous, example to illustrate the lack of correspondence between early domains and seedling regions is the formation of the cotyledons. These originate from the apical domain but also incorporate cells from the central domain (Fig. 2D). The imperfect correspondence of early embryo domains and seedling regions that emerges from the fate map suggests that non-cell-autonomous mechanisms operate to refine the apical-basal pattern.

Despite the absence of a strict correlation between the three early domains and the different seedling regions, genetic analysis in Arabidopsis suggests that the early domains are relevant for pattern formation. Mutants defective in the formation of the main seedling regions along the apical-basal axis display early aberrations in cell division patterns within the corresponding domains (Mayer et al., 1991; Berleth and Jürgens, 1993; Torres-Ruiz et al., 1996; Willemsen et al., 1998). gurke 


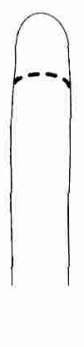

A

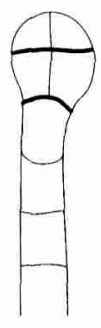

B

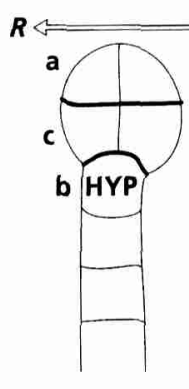

C

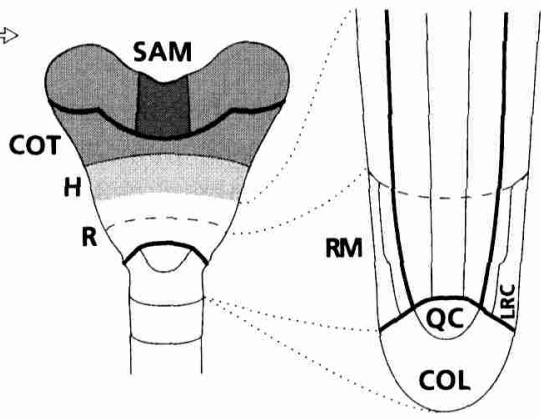

D

E

Fig. 2 Fate map of the Arabidopsis embryo. Stages and axes as in Fig. 1. a, apical region; c, central region; b, basal region; HYP, hypophyseal cell; SAM, shoot apical meristem; COT, cotyledons; H, hypocotyl; R, root; RM, root meristem; QC, quiescent center; COL, columella; LRC, lateral root cap.

$(g k)$ mutants are affected in the apical domain and are defective in the formation of cotyledons and shoot apical meristem (Torres-Ruiz et al., 1996). fackel ( $f k$ ) mutants affect the central domain and hypocotyl formation (Mayer et al., 1991). monopteros $(\mathrm{mp})$ mutants are defective in the formation of the central domain and the basal domain, and strong alleles lack root and hypocotyl (Berleth and Jürgens, 1993). hobbit ( $h b t)$ mutants are disturbed in basal domain formation and they lack the root meristem (Willemsen et al., 1998). All four genes do not necessarily control region identity directly, but may be involved in region-specific aspects of cellular differentiation. Phenotypic defects at early stages are described for the $m p$ and $h b t$ mutants, both required for root development. In contrast, the $g k$ and $f k$ defects become apparent at a later stage of embryogenesis (Torres-Ruiz et al., 1996; Laux and Jürgens, 1997). These differences in manifestation of first detectable phenotypes may originate from a sequential patterning mechanism, with early specification of the basal region and later specification of more apical regions. Alternatively, they may reflect the occurrence of characteristic cell divisions in the basal domain that allow the detection of perturbations at an earlier stage. In any case, root-defective embryo mutants display the earliest reported domain-specific embryo defects correlated with a loss of regional identity, and we will discuss them in some detail.

\section{The HOBBIT Gene and the Basal Domain}

The basal domain encompasses the hypophyseal cell, and anatomical as well as clonal analysis shows that this cell divides stereotypically to give rise to quiescent center and columella root cap cells in the seedling root tip (Figs. 2C-E; Dolan et al., 1994; Scheres et al., 1994). Mutations in the HBT gene result in aberrant de- 
velopment of the basal domain (Willemsen et al., 1998). In strong $h b t$ mutants, the characteristic cell division pattern of the hypophyseal cell is not observed, a quiescent center is not present structurally and functionally, and markers for columella root cap are not expressed (van den Berg et al., 1997; Willemsen et al., 1998). The hbt mutant phenotype suggests that the corresponding gene is required in the basal domain to establish the appropriate cell types. Early molecular markers of regional and cellular identity will be required to assess whether aberrant cell division patterns in the basal region of $h b t$ embryos represent lost or changed regional identity. Molecular cloning and expression analysis of the $H B T$ gene should contribute further to this issue.

The hbt embryo phenotype is consistent with the view that cell-cell interactions refine the apical-basal pattern. The defects in $h b t$ mutants are restricted to the progeny of a single cell in the basal region at early stages but spread to an immediately adjacent cell tier at the heart stage of embryogenesis (Fig. 2D). At that stage, the stem cells ("initials") of the root meristem should be defined in this cell tier. In wild-type plants, the initials perform ordered cell divisions that extend cell files to give rise to the root meristem. The characteristic cell division pattern of initial cells is not observed in the corresponding cell tier of $h b t$ mutants. Furthermore, a new cell type, the lateral root cap that should originate from this tier, is not specified in $h b t$ mutants by both anatomical and marker gene expression criteria (Willemsen et al., 1998).

An attractive view is that $h b t$-dependent cell signaling across the domain boundaries defines the adjacent cell layer to become the root meristem with lateral root cap, although the nonautonomy of $H B T$ requirement in these cells remains to be proven. A patterning mechanism with early establishment of three domains, followed by interactions at the boundaries of the domains to specify seedling regions, is reminiscent of signaling events at boundaries during animal development. For example, $g l p-1$ transmembrane signaling acts during the specification of cells at the boundary of anterior and posterior cell progeny in C. elegans (Priess et al., 1987; Evans et al., 1994) and hedgehog signaling instructs cells at the boundary of anterior and posterior compartments in Drosophila (Lee et al., 1992).

\section{The MONOPTEROS Gene and the Central Domain}

monopteros mutants are defective in root and hypocotyl formation and display aberrant cell division patterns in the basal and central domains of the early embryo (Figs. 2C and 2D; Berleth and Jürgens, 1993). In the basal domain, the normal division pattern of the hypophyseal cell does not occur. In the central domain, cells do not elongate properly to establish the embryo axis that should be formed by this region. $m p$ mutants display defects in vascular tissue formation at all stages of development. Vascular strands do not show the linear continuity that characterizes wild-type vascular strand formation, which is attributed to the failure of $m p$ vascular cells to properly establish a cellular axis ("axialize") (Przemeck et al., 1996). 
The formation of continuous vascular strands can be promoted by the plant hormone auxin and has been postulated to require auxin transport (Sachs, 1991). Interestingly, the recent cloning of the $M P$ gene provides a link to auxin, as it encodes a transcription factor with a motif that has been shown to bind to promoter elements of auxin-inducible genes (Ulmasov et al., 1997; Hardtke and Berleth, 1998). Therefore, the primary role of the $M P$ gene may be to respond to auxin transport to mediate the expression of downstream genes involved in appropriately oriented cell axialization. In early embryo development, the $M P$ gene would in this view promote axialization of cells in the central domain, consistent with the gradual restriction of its embryonic expression to the most axialized - vascularcells (Hardtke and Berleth, 1998). How does a role of the MP gene in cell axialization relate to its requirement for the development of the basal domain? One possibility is the $M P$-mediated axialization in the central domain promotes a signal that is required to activate genes like $H B T$ that in turn specify the basal domain. The question whether $M P$ requirement in the basal domain is indeed non-cell-autonomous should be addressed by mosaic analysis, but as a preliminary step, it will be interesting to verify whether $M P$ expression can be detected in the hypophyseal cell region.

In summary, two genes are now identified that are required for the development of the basal region from the stage that this region is recognizable in the embryo. A number of genes which mutate to similar phenotypes have been reported, but their mutation frequency is low, suggesting that they are not simple loss-of-function mutants (Berleth et al., 1996; Scheres et al., 1996). Future goals will be to establish the relationship between the $H B T$ and $M P$ gene activities and to identify upstream regulators. Given the early appearance of the $h b t$ and $m p$ phenotypes, such regulators may uncover primary steps in apical-basal patterning.

\section{Formation of the Radial Axis}

While at least some ideas concerning the formation of the apical-basal axis have emerged from the studies mentioned in Section IIA, it remains mysterious how the radial axis is specified during embryogenesis. The first manifestation of the radial axis is the formation of the outer protoderm layer, the incipient epidermis (Fig. 1C). It may be relevant that plant zygotes have been shown to be coated with a cuticle layer, a feature that is retained in epidermal cells only (Bruck and Walker, 1985). The ATML1 gene, encoding a homeodomain protein, is also expressed prior to the separation of an outer layer, and downregulated in inner daughter cells thereafter (Lu et al., 1996). Hence, epidermal cell fate could be positively instructed by their position at the periphery. Therefore it has been speculated that radial axis formation results in an "outer" cue to specify future epidermis (Laux and Jürgens, 1997). Such a cue could be localized to the outer cell wall (or membrane) or it could be the result of signals from surrounding endosperm cells. 


\section{Radial Pattern Formation}

Radial axis specification may mark the outer embryo surface or result in some other initial asymmetry, and the next question is how such cues lead to pattern formation. One possibility is that the withdrawal of an outer cue leads to a second cell type. Analysis of expression of the ATLTP 1 gene in mutant backgrounds has provided support for this notion. The ATLTP1 gene is normally expressed in the outer layer of the globular stage embryo but expression becomes ubiquitous in knolle mutants that do not complete cytokinesis due to a defective syntaxin (Lukowitz et al., 1996; Vroemen et al., 1996; Lauber et al., 1997). Cytokinesis may thus be required to separate inner cells from an outer cue to allow alternative fates. The inner cells continue to form a new layer, which could be specified in turn by signal exchange with the outer cell layer, leading to the three main tissues, epidermis, ground tissue, and vascular tissue (Figs. 1C-E). In theory, genetic dissection should provide genes involved in such a patterning scenario, for example genes whose disruption causes the absence or duplication of major tissue layers. However, no genes that are involved in specification of the major tissue layers in response to early radial patterning have been identified by phenotype. Candidate tissue identity genes may be identified by alternative means, e.g., based on their expression pattern. An example is the homeodomain-encoding ATML1 gene that is expressed in the prospective embryonic epidermis (Lu et al., 1996). Reverse genetics approaches now provide the means to analyze such genes at the functional level.

Genes may mutate to a phenotype that at first sight suggests involvement in radial pattern formation, but they may have different functions upon closer inspection. For example, the defective vascular development in $m p$ mutants warrants some discussion on the relation between $M P$ gene function and radial pattern formation. $m p$ mutant organs contain all classes of differentiated vascular cell types, but the cells do not axialize properly (Przemeck et al., 1996). Therefore, the MP gene seems not involved in specification per se of vascular cells during radial patterning. However, recessive $m p$ alleles with a similar strong phenotype may not be nulls (Hardtke and Berleth, 1998), which does not entirely rule out that complete loss of $M P$ function may interfere with vascular cell specification. Nevertheless, the initially broad $M P$ gene expression domain in the embryo that becomes confined to vascular tissue only at later stages (Hardtke and Berleth, 1998) is consistent with the notion that the $M P$ gene has no primary role in cell type specification.

The inability to identify radial patterning mutants involved in early steps may reflect early lethality of such mutants. A class of early lethal mutants has been described in Arabidopsis (Meinke, 1986) but the lack of early markers hampers a detailed analysis of patterning defects within this class. Recent advances in finding genes that mark the major tissues by their expression should alleviate this problem. The lack of radial patterning mutants may also reflect extensive redundancy 
in embryo patterning mechanisms. One striking example of such redundancy has been reported recently in a case where two genes involved in embryonic organ separation and meristem establishment were identified only because a double mutant was fortuitously identified (Aida et al., 1997). Again, gene isolation methods such as gene or enhancer trap strategies that are independent of mutant phenotype provide an alternative approach to cope with redundant genes.

\section{Subspecification of Radial Pattern Elements}

While the patterning of major tissue layers remains almost uncharted territory, more information is becoming available about later steps. Genes involved in epidermal subspecification were identified in both shoot- and root-mutant screens, but many of the ones involved in shoot epidermal patterning function in roots also (Huilskamp et al., 1994; Dolan and Roberts, 1995a). Other genetic loci involved in the subspecification of the embryonic tissue layers have in several instances emerged from screens for root mutants. The root contains the most simple and basic extension of the radial organization of the plant embryo axis in three main tissues (Fig. 1E). Underneath the outer epidermal layer there are two layers of ground tissue, the cortical parenchyma (cortex hereafter) and endodermis. The inner vascular bundle, with a small number of specialized conducting cells and associated cell types, is enclosed by the pericycle layer. Because of the simple tissue pattern in roots, defects within tissue layers can be readily recognized and traced back to corresponding defects in the embryo (Benfey et al., 1993; Scheres et al., 1995). In the following sections, we will discuss genes that are relevant for subspecification events, with emphasis on the uncomplicated root system.

a. Epidermis. In Arabidopsis roots, the epidermis consists of alternating files with two different cell fates: trichoblast and atrichoblast (hair-bearing and hairless, Fig. 3). Alterations in this pattern of epidermal subspecification can be readily detected and several genes have been shown to be involved. Recessive mutations in the TRANSPARENT TESTA GLABRA (TTG) gene and in the homeobox gene GLABRA2 (GL2) result in roots with hair cells only (Galway et al., 1994; Rerie et al., 1994; Masucci et al., 1996). These genes therefore act as negative regulators of the hair cell fate. $t$ tg mutants can be rescued by overexpression of the maize $R$ gene (Lloyd et al., 1994), which has sequence similarity to myc-related transcription factors, indicating that an Arabidopsis homologue of the $R$ gene operates downstream of $T T G$.

Two observations implicate the TTG gene as an upstream regulator of GL2. First, in $g l 2$ mutants but not in $t t g$ mutants some cellular characteristics of hairless cells remain. Notably, the remaining hairless cell-specific traits in gl2 mutants appear at the correct position (Masucci et al., 1996), suggesting that GL2 is not involved in setting up the alternating pattern but responds to it and mediates a subset of hairless cell differentiation processes. In addition, GL2 transcription is 


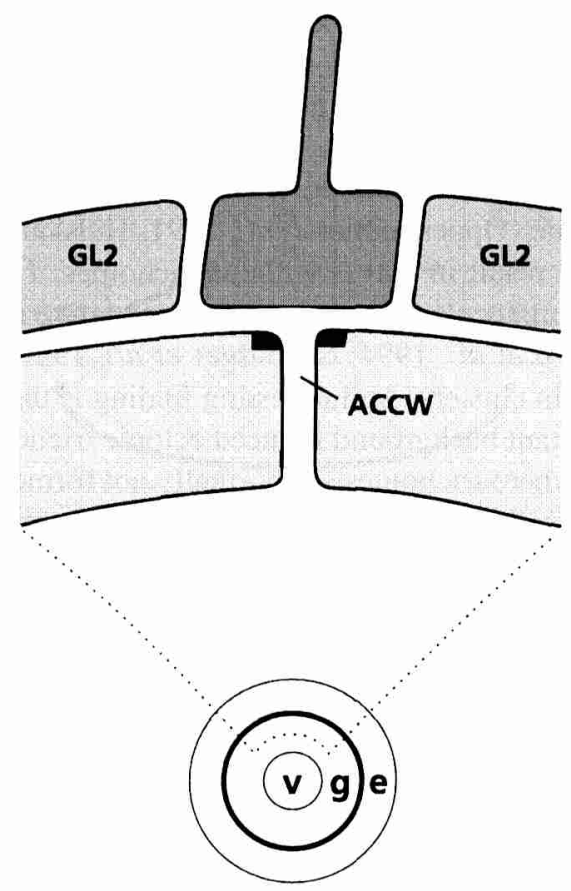

Fig. 3 Hair cell patterning in the root epidermis. In Arabidopsis roots, the epidermis consists of alternating files of hair-bearing and hairless cells. Hair cells are invariantly located over anticlinal cortical cell walls (ACCW) between two cells of the underlying cortex layer. Hair cell fate is dependent on the distance to the ACCW, and extracellular cues (black) may reside in a narrow domain centering on the anticlinal wall. The GL2 gene acts to repress hair fate and is expressed in hairless cells. Transverse section as in Fig. 1E.

lowered in ttg mutants (Di Christina et al., 1996). The GL2 gene is expressed predominantly in hairless cell files, implying that it acts cell-autonomously to repress hair fate, and this expression in alternating cell files is set up during embryogenesis (Fig. 3; Berger et al., 1998a).

Recessive mutations in the CAPRICE (CPC) gene show that it is required for the hair cell fate (Wada et al., 1997). CPC encodes a $m y b$-like transcription factor, and one awaits data on its localization and interaction with $G L 2$ as well as localization of the site of action of TTG, to understand how these transcription factors regulate epidermal subspecification.

In summary, subspecification of the root epidermis involves a suite of transcription factors and one upstream regulator. Notably, these genes are also involved in the specification of hairs of the shoot epidermis (trichomes) but with opposite roles: $T T G$ is required to specify the trichome fate and to regulate trichome distribution, and $G L 2$ promotes trichome outgrowth (Hülskamp et al., 1994). CPC 
overexpression has a negative effect on trichome formation (Wada et al., 1997), but it is unclear whether this reflects a negative input of CPC in vivo or is an effect of promiscuous interactions. Two genes without apparent function in the root epidermis are also involved in trichome patterning. GLABROUS1 (GL1), with sequence similarity to $m y b$-like transcription factors, is required together with TTG to specify trichome fate (Oppenheimer et al., 1991; Hülskamp et al., 1994). Mutations in these genes result in leaves without trichomes. TRIPTYCHON (TRY), with as yet unknown molecular identity, acts as a negative regulator of trichome distribution (Hülskamp et al., 1994; Schnittger et al., 1998): in try mutants trichomes often appear in clusters. An interesting finding is that ubiquitous expression of GLI in try mutant background induced ectopic trichomes, not only on the epidermis of organs where trichomes are normally not formed but also in subepidermal ground tissue cells (Schnittger et al., 1998). The subepidermal trichomes are distributed without guidance of the epidermal trichomes (although lateral inhibition between layers seems to occur), which indicates that also the trichome patterning mechanism is induced in the ground tissue layer. This important finding shows that developmental constraints in plant tissue layers are not rigid and that activation of a cell-type specific pathway can mediate both cell specification and patterning.

b. Ground Tissue. The embryonic ground tissue gives rise to cortical parenchyma, of which two layers are present in the hypocotyl and one in the root, and to the inner endodermis. To achieve this, the single layer of ground tissue in the globular embryo performs two periclinal divisions in the hypocotyl region and a single periclinal division in the root region. These divisions are asymmetric in that the daughter cells have different fates. In the root meristem of many Arabidopsis ecotypes, a single stem or initial cell layer continues after embryogenesis to produce daughter cells that give rise to both endodermis and cortex by asymmetric cell division (Fig. 4).

Genes first identified on the basis of a root phenotype have enabled an analysis of the subdivision of ground tissue in two different cell types. Mutations in the SHORTROOT (SHR) and SCARECROW (SCR) genes interfere with both embryonic and postembryonic asymmetric divisions (Benfey et al., 1993; Scheres et al., 1995). shr and scr mutants were identified by virtue of their secondary phenotype: a reduction in root growth. In $s h r$ mutants, the remaining cell layer lacks endodermal attributes whereas the layer that remains in scr mutants expresses both cortical and endodermal markers (Di Laurenzio et al., 1996). Apparently, shr is required for both the asymmetric cell division and the acquisition of endodermal cell fate, whereas scr, based on these observations, would be required exclusively for the execution of the cell division. The $S C R$ gene encodes a putative transcription factor, which provides no direct relation to asymmetric cell division. Interestingly, the gene is not only expressed in embryonic ground tissue cells and root meri- 


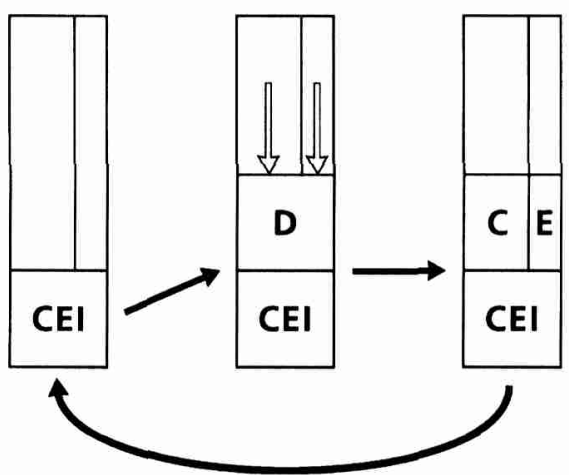

Fig. 4 Patterning and signaling in the ground tissue. In the Arabidopsis root meristem, a cortex/endodermal initial (CEI) divides to produce daughter cells (D) that give rise to both cortex (C) and inner endodermis $(E)$ by asymmetric cell division. Continuous positional information in the root apex reaches the position of the initial cells, indicating that more mature cells act as a patterning template for newly generated cells (open arrows).

stem initials at the time of asymmetric cell division, but transcription remains active in the endodermal layer (Di Laurenzio et al., 1996). The significance of the endodermal expression in roots is not clear from the root phenotype, but newly isolated scr and shr alleles have hinted to a scr function in the inner ground tissue layer. These alleles were recovered in a screen for shoot gravitropic mutants. It was shown that the mutants lack a normal endodermis based on the absence of sedimented (gravity-sensing) amyloplasts in the hypocotyl and in the shoot meristemderived stem (Fukaki et al., 1998). This observation makes two important points. First, the $S C R$ and $S H R$ genes are involved in the radial organization of not only the embryo axis but also the shoot meristem-derived organs. Second, an abnormal marker in the endodermis implies that the $S C R$ gene, just like $S H R$, is involved in asymmetric cell division but could play a role in aspects of inner cell fate that are not readily detectable in the root as well. A continued expression in the inner cell layer is consistent with a dual function for SCR.

c. Vascular Tissue. Within the vascular tissue, several cell types arise in an ordered spacing pattern. In the Arabidopsis root, two metabolite-conducting phloem elements are located on opposite poles of the vascular bundle, and between them there are single water-conducting xylem elements. In other regions of the plant, these elements also coexist within the vascular bundle in a different arrangement. What regulates the spacing pattern of phloem and xylem cells within the vascular tissue? The wooden leg (wol) mutant provides a genetic entrance into this issue. In this mutant, only xylem forms within the vascular bundle of the root (Scheres et al., 1995). Phloem cells are, however, present in the upper part of the 
hypocotyl and in leaves, demonstrating the ability of the mutant to differentiate this cell type. During embryogenesis, wol mutants form too few cells in the vascular tissue. The number of cells in this region of wol mutants can be increased by constructing double mutants with fass $(f s)$, a mutant that results in supernumerary cell divisions (Torres-Ruiz and Jürgens, 1994). In the wol fs double mutant the root now produces phloem cells again, indicating that the amount of available cells in the vascular region is critical for correct pattern formation in wol mutants and that xylem prevails over other cell fates in that case (Scheres et al., 1995). The spacing pattern of phloem and xylem during normal vascular development could signify that such first-specified xylem becomes a source of lateral inhibitory signals for phloem development.

In summary, a handful of genes have been identified with a role in subspecification of the primary tissue layers, and the patterning mechanisms involved are now open for investigation.

\section{Postembryonic Perpetuation of Cellular Pattern}

While insights into axis formation and early patterning will have to emerge from studies on embryogenesis, during which a mature embryo is produced in the protective seed coat, the story of plant development goes well beyond this phase. When a seed germinates and the mature embryo gives rise to a juvenile plant (the seedling), most of its cells fully differentiate. However, the descendants of the stem cell populations within the shoot and root meristems are exceptional. These are mitotically reactivated and they extend and modify the basic embryonic tissue pattern to give rise to the adult plant (Steeves and Sussex, 1989). This process continues throughout the entire life span of the plant. To understand the postembryonic chapter of plant development, it is necessary to address the question how newly produced cells in the meristems differentiate into the appropriate cell type. Clonal analysis in shoot meristems demonstrates that the fate of newly generated cells is position- and not lineage-dependent (for Arabidopsis, see Furner and Pumfrey (1992), Irish and Sussex (1992), and Schnittger et al. (1996)). In the root meristem, cell lineages are more regular but clonal analysis demonstrates that also in this meristem position determines cell identity (Scheres et al., 1994; Grierson, 1997). Moreover, the transparent Arabidopsis root has facilitated the manipulation of cells with a laser beam to analyze positional components in cell specification. Laser ablation results in replacement and position-dependent differentiation of daughter cells from neighboring tissues in all instances tested (van den Berg et al., 1995).

Several mechanisms can account for the ability of meristematic cells to continuously assess position and differentiate appropriately. The perfect continuity of pattern in tissue formed before and after embryogenesis implies that the challenge in understanding meristems seems to be not whether but how they elaborate on embryonic mechanisms or prepatterns. 


\section{A. Prepatterning of Meristem Cells?}

In animal systems, prepatterning genes define regions prior to visible differences, either by dictating fate cell-autonomously or by conferring competence to respond to further patterning cues. In Drosophila, for example, transcriptional regulators of the Iroquois complex allow expression of the proneural genes that select bristle-forming cells in specific domains (Gomez-Skarmeta et al., 1996; Kehl et al., 1998). In the context of plant meristems, prepatterning genes should define tissues before the meristems become active. What is the evidence for such genes and how would they dictate pattern?

In the root meristem, the stem cells of the different tissues-epidermis, ground tissue, vascular tissue, and root cap-are anatomically distinct from the moment that they are born, indicating that they are specified differently (Dolan et al., 1993). Gene expression patterns also reveal extensive differences between stem cell groups (van den Berg et al., 1995; Berger et al., 1998a; Scheres and Wolkenfelt, 1998). The $S C R$ gene, encoding a putative transcription factor essential for the formation of specific cell types (Section IID1b), marks the cortical stem cells and their endodermal daughters, and it displays layer-specific expression prior to the formation of the root meristem (Di Laurenzio et al., 1996). The GL2 gene, encoding a homeodomain transcription factor, is expressed in epidermal nonhair files within the meristem and it is required to maintain the nonhair fate of these cells (Section IID1a; Masucci et al., 1996). GL2 expression is restricted to the non-hairforming cell files in the mature embryo, but only when the root meristem initials already display their characteristic stem cell-like division pattern. In conclusion, anatomical and gene expression data show that cells within the postembryonic root meristem are not naïve and that some but not all genes with a patterning phenotype are expressed prior to the emergence of the meristem.

In the shoot meristem, separate cell layers, in the case of the epidermal L1 layer fated to give rise to a single tissue, can be detected by anatomical criteria (Fig. 5). The $A T M L 1$ gene, encoding a putative transcription factor, is an example of a gene expressed specifically in all cells of the L1 layer, prior to the emergence of the shoot meristem (Lu et al., 1996). As in the root meristem, the emerging picture is that many, if not all, cells within meristems express tissue-specific genes, most of them already during embryogenesis.

The clonal analyses and laser ablations discussed in Section III, however, show that cells within meristems have flexible fate and might constitute single equivalence groups, indicating that the previously established expression patterns do not dictate the fate of cells in a stable, cell-autonomous way.

\section{B. What Are the Relevant Prepatterning Cues?}

Cells that switch position postembryonically can start to express genes whose expression is normally initiated during embryogenesis. A well-documented example 


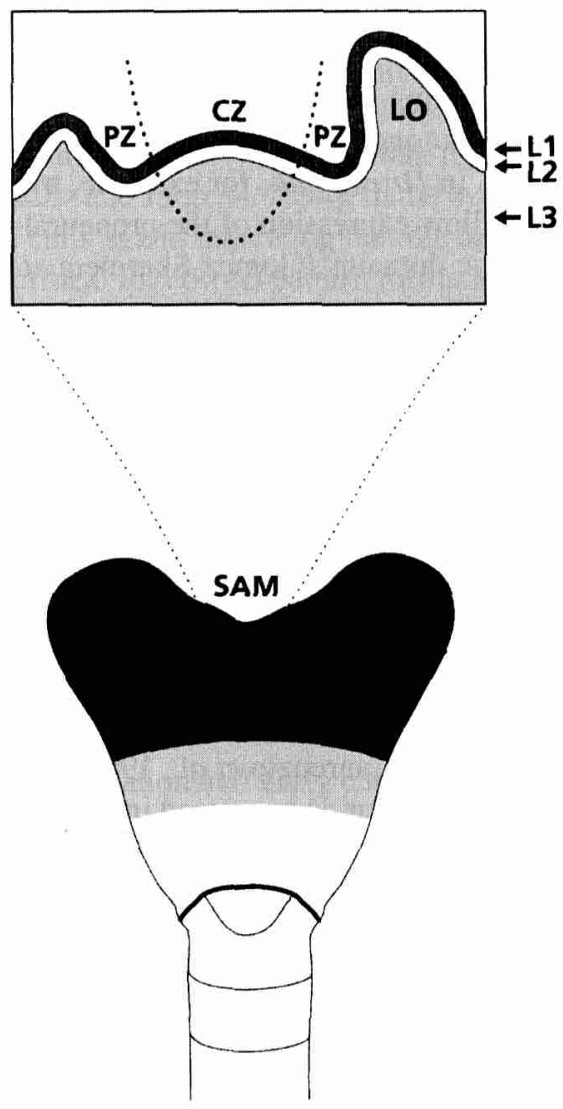

Fig. 5 Shoot meristem organization. The shoot meristem can be divided into layers and zones. Separate cell layers ( $\mathrm{L} 1, \mathrm{~L} 2$, and $\mathrm{L} 3)$ can be detected by anatomical criteria. The region corresponding to the central zone (CZ) consists of stem cells with reduced division rates and is surrounded by a peripheral zone (PZ) of more rapidly dividing cells where lateral organs (LO) or meristems initiate.

involves hair cell patterning in the root epidermis. Hair cells are invariantly located over anticlinal cell walls between two cells of the underlying cell layer (Fig. 3). The $G L 2$ gene, required to execute the nonhair fate in the root epidermis, is expressed accordingly in the remaining cells already in the mature embryo (Berger et al., 1998a). With low frequency, cells overlying the anticlinal cell wall perform a longitudinal division that creates two cells, which subsequently form two clones. One of these clones is displaced from the underlying anticlinal cell wall. Analysis of GL2 transcription in such displaced cells reveals that gene is now expressed (Berger et al., 1998b). Hence GL2 gene expression does not form a positional reference in the meristem by itself, but it rather remains responsive to cues of unknown nature. We should like to know the nature of these and other cues that have 
been demonstrated to direct cell fate in meristems. The first clues have been obtained about the direction of such positional cues involved in the specification of cell types in all three major root tissues, the hair/nonhair cells in the epidermal cell layer, the cortex/endodermis derived from the ground tissue, and the vascular tissue. These will be discussed in the following sections.

\section{Epidermis}

The cues that govern the hair/nonhair cell fate decision are present throughout the root meristem, as revealed by the inspection of the early and late hair/hairless clones discussed in Section IIIB (Berger et al., 1998a, 1998b). Cell fate is dependent in a precise way on the distance to the anticlinal wall, and a variety of ablations of neighboring cells are not able to disturb position-dependent differentiation. Although rigorous proof of the lack of signals emanating from neighbors requires complete isolation of epidermal cells - an experiment that is obstructed by technical difficulties-it is tempting to conclude that extracellular cues may reside in a narrow domain centering on the anticlinal cortical wall (Fig. 3; Berger et al., 1998a).

The plant hormone ethylene governs a number of developmental processes in plants, and its synthesis and signal transduction are beginning to be understood in some detail (Ecker, 1995; Fluhr, 1998). Root hair formation is affected by modulation of ethylene synthesis and perception, either genetically or with precursors/ inhibitors (Dolan et al., 1994; Masucci and Schiefelbein, 1994; Tanimoto et al., 1995). These studies indicate that ethylene signaling is necessary and sufficient for root hair formation. Ethylene can still affect cells at relatively advanced stages of cell differentiation (Masucci and Schiefelbein, 1996). Is this plant hormone involved in maintaining a-potentially extracellular-cue that determines epidermal cell fate, is it involved in the initial establishment of this cue, or is ethylene acting in a pathway independent from cortical domains and transcription factors such as $G L 2$ ? More experiments will be necessary to elucidate the relation between transcription factors, cortical wall-dependent differentiation, and ethylene.

\section{Cortex and Endodermis}

Continuous positional information in the root apex reaches the position of the stem cells for all the different tissues, as cell invasions in this region result in positiondependent fate switching (van den Berg et al., 1995). What is the origin of these cues? In the ground tissue, it has been investigated how the meristematic stem cells obtain the information to give rise to two different cell types (Fig. 4). When ground tissue stem cells that normally give rise to cortex and endodermis are isolated from their own tissue by laser ablation of more mature daughters, they can still proliferate but no longer perform the characteristic asymmetric cell division to create 
both layers (van den Berg et al., 1995). This indicates that more mature cells act as a patterning template for newly generated cells (Fig. 4). A guiding effect of more mature cells on newly added cells seems a reasonable strategy to ensure that a pattern that is set up in the protective environment within the seed coat is perpetuated throughout development. More evidence and studies on the molecular mechanisms involved are needed to substantiate this "patterning template" idea.

It may be of interest that cytoplasmic connections between cells in the root meristem reminiscent of gap junctions-plasmodesmata-have been shown in several instances to establish layer-specific connections (Duckett et al., 1994; Oparka et al., 1994; McLean et al., 1997). In the shoot meristem, it has been proposed that transcription factors may be routed through plasmodesmata (Lucas $e t$ al., 1995). Additional experiments will be required to test whether positional cues utilize plasmodesmata, thereby providing a direction to positional signaling. Relevant questions are whether prepatterned genes like $S C R$ are also required to maintain the postembryonic pattern and whether involvement in maintenance of pattern by transcription factors like $S C R$ could involve directional routing via plasmodesmata. Continuous deployment of patterning genes is not unprecedented. In Drosophila, the Hedgehog (HH) gene product seems to signal continuously across $\mathrm{A} / \mathrm{P}$ boundaries to mediate patterning. $\mathrm{HH}$ is first active in the cellularized embryo and continues to be active in the developing imaginal discs (Lee $e t$ al., 1992; Basler and Struhl, 1994; Strigini and Cohen, 1997). A critical test whether patterning genes act continuously in plants has to await accurate assessment of the temporal requirement of embryonic patterning genes.

An alternative mechanism could underlie the patterning template scenario that is outlined above. Embryonic pattern formation can yield a prepattern of cells that subsequently mediate position-dependent cell specification by postembryonic mechanisms unrelated to those that are used to set up the prepattern. An example of a new mechanism operating after prepatterning may be the "community effect" that is proposed to enable Xenopus mesoderm cells to progress to muscle or notochord differentiation. It has been shown that a minimal number of mesoderm cells is required for muscle cell differentiation (Gurdon et al., 1993). A mesoderm-derived "community factor" is thought to be in part responsible for activating mesoderm differentiation (Carnac and Gurdon, 1997). One may describe this effect in more general terms: as soon as embryonic events have established a sufficiently large pool of a particular cell type, these cells mutually reinforce their fate. In plant tissues, reinforcement mechanisms would have to be directional-as indicated by laser ablation experiments (van den Berg et al., 1995)— to ensure the maintenance of patterns of single-cell width.

\section{Vascular Tissue}

A feed-forward mechanism to recruit newly generated cells into existent tissue layers may also operate in the vascular tissue. As discussed in Section IIB2, the MP 
gene is required to promote vascularization in the root/hypocotyl region of the embryo (Berleth and Jürgens, 1993). When MP levels are reduced, basal cells are not recruited to enter the vascular differentiation pathway, although the gene is not required for vascular differentiation per se but rather for the connection of vascular cells to give continuous strands (Przemeck et al., 1996). Apparently, vascular cell continuity is required for ongoing specification. Hence, also in this case, an existing pattern may be maintained by directional recruitment, perhaps by directional auxin transport (Hardtke and Berleth, 1998).

The overall conclusion is that as yet no evidence has been found for prepatterning genes as cell-autonomous organizers, such as at the A/P boundaries in fly development. There is, however, evidence for the localization of positional cues or for the direction in which cues are delivered. In the case of epidermal subspecification, positional information may be laid down in localized extracellular domains. For continuous vascular development and for ground tissue subspecification, maturing pattern elements may be involved in the directional transport of signals to recruit new cells. Are reinforcement mechanisms community effects, with the additional feature that tissue layers can promote differentiation of their own kind in a directional fashion? In that case, the mature tissues would be the "organizers" of cellular pattern in the meristems. This exciting issue will have to be addressed by analysis at the molecular level.

\section{Control of Cell Division during Development}

Throughout the development of all multicellular organisms, cell divisions in time and space accompany the formation of a specific pattern of different cell types, tissues, and organs. Unlike the situation in animals, plant development is predominantly postembryonic and relies on the activity of apical meristems, pattern elements that are first established during embryogenesis. Meristems are defined as localized clusters of dividing cells. Two types of cell divisions contribute to the development of the mature plant. Proliferative cell divisions lead to the production of more cells of the same type within a cell file or tissue. Formative cell divisions include asymmetric cell divisions that give rise to different cell types and oriented cell divisions whereby additional cell layers are created (reviewed in Jürgens, 1996).

Cell division is involved in three aspects of postembryonic plant development occurring in overlapping stages. (i) Different cell fates continue to be generated within the meristems involving positional information and asymmetric cell divisions. Cell fate specification during pattern formation may regulate cell division. In plants, it is an important issue whether pattern formation in turn depends on precise number and sequence of cell division. (ii) A second feature concerns the activation and maintenance of the meristems. Postembryonic development begins when the seed germinates and cell division is reactivated in the shoot and root api- 
cal meristems. To ensure continued cell production, it is essential that an active meristem is maintained. (iii) The third aspect involves the growth and morphogenesis that give rise to the size and distinct shape of cells, organs, and the organism itself. Growth is a combination of increasing numbers of cells and cell expansion and involves mostly proliferative cell divisions. Morphogenesis shapes the organism through the combined activities of proliferative and formative cell division, cell expansion, cell death, and, in animals, cell movement. Since cell walls constrain cell movements, the relevant issue here is whether precise control of cell division is essential for plant morphogenesis.

We will focus mainly on the Arabidopsis root meristem to illustrate the role of cell division during the development stages outlined here, and we will also take into account important advances in identifying genes involved in regulation of cell division in the shoot meristem.

\section{A. Pattern Formation Can Be Uncoupled from Cell Division}

During Arabidopsis embryogenesis the sequence of cell division is very regular, enabling seedling structures to be traced back to groups of cells in the early embryo. Recessive mutations in the FASS (FS) and TONNEAU (TON-1, TON-2) genes alter cell division sequences and orientation from the zygote stage onward, and by the octant stage the mutant embryos look abnormal (Torres-Ruiz and Jürgens, 1994; Traas et al., 1995). Whereas no primordia of seedling structures can be recognized by morphological criteria at the heart stage, all elements of the body pattern are differentiated in $f s$ and ton seedlings, although their morphology is abnormal. At the cellular level, $f s$ and ton mutations affect cell elongation and orientation of cell division. For example, the root lacks the regular arrangement of cell files found in the wild type and shows irregularly enlarged cells. Nevertheless, all cell types are present. These results show that $f s$ and ton mutants do not affect pattern formation, suggesting that the regularity of cell division is not instrumental in pattern formation. Similarly, irregularity in cell division coupled to precise patterning appears to exist in nature; in embryos of plant species such as cotton the pattern of cell division is not at all regular and yet the seedling has the same body pattern as Arabidopsis (Pollock and Jensen, 1964).

The interdependence of patterning from cell division is supported by analysis of tobacco plants transformed with a dominant negative (DN) form of the heterologous Arabidopsis CDC2A gene (Hemerly et al., 1995). Cell division is slowed down but DN plants appear only slightly smaller and morphologically normal due to increased cell sizes. Cross sections-through a leaf, cotyledon, and root show that all cell layers and cell types are present in a normal arrangement, indicating pattern formation does not depend on precise cell numbers. In addition, the normally very regular cell division sequences in the root meristem of tobacco is disturbed in DN plants, particularly in the apical region affecting the quiescent cen- 
ter and initials, apparently without interfering in the patterning of the different root tissues.

Pattern formation and cell division have also been uncoupled in animals. In Drosophila, a temperature-sensitive (TS) CDC2 mutation has been used to inhibit cell division locally and during different developmental stages (Weigmann et al., 1997). Wing size and shape are normal when few cell divisions are blocked because cell size increases. Notably, the presence of fewer larger cells has no significant effect on the pattern of veins in the wing and expression of the patterning gene $D P P$ and its targets $O M B$ and SPALT in the wing disc or $O D D$ in the leg disk. Thus the processes that determine the pattern and sizes of expression domains of these genes can continue in the absence of cell division.

Taken together, the results suggest that in plants and animals patterning cues are relatively independent of the number of cells and, in plants, plane of cell division. For animals this translates to long-range cues that are assessed in a distance- or volume-dependent manner. Such long-range cues have not been identified in plants. However, a patterning mechanism based on cell-cell communication and reinforcement signals (Section III) would still allow patterning when cell numbers and sizes are deregulated.

\section{B. Cell Fate Specification Can Regulate Cell Division}

Mechanisms whereby cell fate specification leads to patterned regulation of cell division are common in animal development (Cohen, 1996; Kim et al., 1996; Schnabel, 1996; Folette and O'Farrell, 1997). The perhaps simplest form of this regulation is exemplified by $C D C 25^{\text {string }}$ expression during fly embryogenesis (Edgar et al., 1994). CDC25 $5^{\text {string }}$ is a phosphatase that removes inhibitory phosphorylation from CDC2. Normal embryonic expression of string requires extensive cis-acting regulatory sequences. string expression is controlled at the transcriptional level and patterned by positional information supplied by a large set of genes that determine many aspects of cell fate. For example, in embryos that are mutant in $t w i s t$, a gene encoding a transcription factor that is specifically expressed in the prospective mesoderm, there is a specific absence of string expression and hence cell division in the mesodermal cells. Apparently, combinations of transcription factors bind to the string promoter and drive its expression in unique patterns resulting in local cell division (Edgar et al., 1994).

Such a relationship between fate specification and cell division may also be characteristic of plant meristems. Recall, for example, that the $S C R$ and $S H R$ genes are involved in asymmetric divisions in the root that generate cortex and endodermis as well as in aspects of endodermal cell fate (Di Laurenzio et al., 1996; Fukaki et al., 1998). We will discuss in some detail recent experiments on the Arabidopsis root epidermis that provide further evidence for control of cell division by cell fate specification. 


\section{Cell Fate Regulates Cell Division in the Root Epidermis}

The alternating files of hair and hairless cells in the root epidermis consist of cells of different sizes. Hairless cells are longer than hair cells at maturity (Dolan et al., 1993), which indicates that hairless cell files produce fewer cells. Clones originating from single hair cells, which give rise to both hair and hairless cells (Section IIIB), also display differential cell length together with differential GL2 expression (Berger et al., 1998b). As the clones increase in size, the number of hairless cells gradually trails the number of hair cells. This is reflected by the ratio of the number of cells in either clone, which increases until it reaches an average maximum. Thus, the cell division rate initially slows down in the hairless clone, allowing these cells to reach their normal larger size. These results show that a change in cell fate can influence cell division rate. Hairless cells were reported to be longer throughout the meristem except around the initials (Beemster and Baskin, 1998; Berger et al., 1998b), showing that differential cell division rate and cell size is normally regulated close to the initial cells of the meristem. Do genes controlling hair cell fate, such as TTG (Section IID1a; Galway et al., 1994), regulate cell division? In $t$ tg mutants, which display ectopic root hair formation, epidermal cell sizes in all cell files are similar (Berger et al., 1998b). These results show that TTG is involved in the control of cell division rate in the epidermis. Furthermore, the normally markedly higher occurrence of longitudinal anticlinal divisions observed in hair cells, resulting in a higher number of clones being derived from these cells, is significantly altered in $\mathrm{ttg}$ mutants (Berger et al., 1998b).

In conclusion, in plants cell fate specification can regulate cell division rate and orientation and this mechanism may contribute to generating different cell sizes.

\section{Activation of Meristems}

Following fertilization, the zygote undergoes cell divisions to produce the embryo with the primary meristems of the shoot and root set up at opposite poles of the apical-basal axis (Fig. 2D). The embryo ceases cell proliferation upon maturation and then enters dormancy until seed germination, when postembryonic development starts and cell division is reactivated in the meristems. As the plant grows, shoots set aside axillary meristems that may initiate secondary branches. The root system branches by forming lateral roots via new meristems generated from nonmeristematic tissue (Steeves and Sussex, 1989; Malamy and Benfey, 1997b).

It is not yet clear whether specific positive input is required for embryonic cell divisions as opposed to postembryonic ones. The PROLIFERA (PRL) gene is zygotically required for embryo development in Arabidopsis (Springer et al., 1995). $P R L$ is likely to represent a general cell division factor since it is related to the MCM2-3-5 family of yeast genes that are required for the initiation of DNA replication. Accordingly, reporter gene expression data reveal that $P R L$ is expressed in 
dividing cells throughout the embryo and mature plant. medea (mea) mutant embryos grow excessively and this growth regulation phenotype is strictly dependent on maternal contribution of the mutant gene (Grossniklaus et al., 1998). The MEA gene, therefore, provides a negative maternal input for the controlled cell proliferation in the embryo. MEA encodes a Polycomb-related protein and it has been suggested that its expression is regulated by genomic imprinting.

\section{Activating the Shoot Meristem}

Activation of the shoot meristem in maize may involve the KNOTTEDI (KNI) gene. $K N 1$ encodes a homeobox protein and is expressed in the cells of the shoot meristem but disappears rapidly from portions of the meristem where leaf primordia or floral organs initiate (Fig. 5; Vollbrecht et al., 1991; Jackson et al., 1994). Transgenic tobacco plants ectopically expressing $K N 1$ in leaves can have adventitious shoot meristems and shoots forming on the leaves (Sinha et al., 1993), showing that $K N I$ is sufficient for induction of cell division when ectopically expressed. The Arabidopsis SHOOT MERISTEMLESS (STM) gene is a homolog of KN1 and shares a closely related RNA expression pattern with KN1 (Long et al., 1996). stm mutants are already defective in the initial formation of the meristem during embryogenesis, indicating a function in establishing the meristem (Long and Barton, 1998). Although the role of STM in activation of the meristem is unclear, analysis of loss-of-function mutants has revealed a role for both STM and KN1 in meristem maintenance (Section IVD1; Clark et al., 1996; Kerstetter et al., 1997).

\section{Activating the Root Meristem}

Several mutants have been obtained that display arrested root growth following germination. The root meristemless $(\mathrm{rml})$ mutants have a root meristem with a normal cellular architecture that undergoes no $(\mathrm{rmll})$ or limited $(\mathrm{rml})$ postembryonic cell division following germination whereas shoot development is reported to be unaffected (Cheng et al., 1995). Interestingly, $r m l l$ lateral roots are able to initiate normally but cell division ceases when the same number of cells as the embryonic root and the $r m l l$ primary root is reached. Histological data on wild-type roots show the number of cells constituting the lateral root prior to meristem activation corresponds to the number in the $r m l l$ mutant (Malamy and Benfey, 1997b). The aberrant lateral root formation 3 (alf3) mutants form densely spaced lateral root primordia that are arrested at a similar stage (Celenza et al., 1995). Unlike the $\mathrm{rml}$ mutants, alf3 mutants can be rescued by applying the plant hormone auxin or its precursor indole, suggesting that the absence of auxin/indole is responsible for the premature arrest in cell division.

These studies indicate that both primary and lateral root formation is a two-stage process: (1) formation of the meristem involving mostly formative cell divisions: 
(2) activation of cell division in the meristem involving mostly proliferative cell divisions. Primary root development and secondary root development seem to share a common end point at which time the $R M L 1$ and $A L F 3$ gene products are required for the activation of the meristem and the continuation of root growth.

a. Environmental Factors Control Cell Division. A characteristic feature of plants is their plastic development in response to external factors, e.g., nutrition, light, and stress. It is now well established that environmental adversity results, at least partly, in the enhanced formation of active oxygen species. Adaptation of plants to stressful conditions involves the recruitment of ascorbic acid (AA), glutathione (GSH), and $\mathrm{NAD}(\mathrm{P}) \mathrm{H}$ for efficient removal of the oxidizing agents (Bowler et al., 1992; May and Leaver, 1993; Babiychuk et al., 1995; Conklin et al., 1996). These molecules that undergo reversible alterations are ideal candidates to act as sensors or even effectors in the control of cell division.

Three lines of evidence indicate that GSH participates in the regulation of cell division in the Arabidopsis root meristem (Sanchez-Fernandez et al., 1997). First, artificially increased endogeneous GSH levels stimulate cell divisions. More mitotic figures are observed within the same zone, indicating an increased cell division rate, but also the length of the meristem is extended compared to controls, resulting in more dividing cells. Both processes contribute to an increased cell production. Under these conditions root growth is slightly enhanced even though cell size is decreased. Second, artificially decreasing GSH levels through treatment with L-buthionine $(S, R)$-sulfoximine (BSO), a specific inhibitor of GSH synthesis, reduces cell divisions. Root growth does not significantly decrease because cell size increases dramatically. Importantly, the inhibition of cell division through BSO can be completely reversed by supplementing GSH, indicating that GSH levels are specifically lowered. Third, in vivo fluorescence labeling of GSH shows that high levels of endogenous GSH are associated with actively dividing cells but not the mitotically inactive quiescent center. This distribution closely parallels that described for the pattern of AA in the maize root meristem (Kerk and Feldman, 1995). The low levels of AA in the quiescent center appear to be actively maintained by the local high level of ascorbate oxidase, suggesting a function for AA in the regulation of cell division. This is consistent with the observation that cells in the quiescent center have extended G1 phases (Clowes, 1975) and that AA may be necessary for G1/S transition in the cell cycle (Liso et al., 1984, 1988; Citterio et al., 1994). Taken together, these results suggest a mechanism that operates to lower the GSH and AA pools or shift their redox balance not only in the quiescent center but also in proximally located cells of the meristem to restrict the extent of the meristematic zone.

These observations imply a direct link between the levels of GSH and/or AA and the plant cell cycle, which parallels results in animal systems. For example, specifically depleting the GSH level in human cells induces oxidative stress. This results in the induction of WAF1 expression, encoding a potent inhibitor of cyclin- 
dependent kinases required for progression from the $\mathrm{G} 1$ into the $\mathrm{S}$ phase of the cell cycle, and cell cycle progression is arrested (Russo et al., 1995). Induction of WAF1 is prevented by pretreating cells with a precursor of GSH. Similarly, other studies indicate the requirement for de novo synthesis of GSH for both entry and progression through the cell cycle (Suthanthiran et al., 1990; Poot et al., 1995). GSH may be a conserved factor in modulating the activity of transcription factors responsible for cell division. Whether this means that, in plants, control of environmental factors has evolved as a mechanism for developmental control is unclear.

\section{Maintaining Meristem Activity}

Maintaining a pool of stem cells is important to ensure a continued existence of the meristem. Substantial progress has been made in identifying genes involved in the maintenance of the stem cell population in the shoot meristem (reviewed in Clark (1997), Meyerowitz (1997a), and Laux and Mayer (1998)). Also in the root, stem cell maintenance by central quiescent cells may be one of the ways to ensure continuous meristem activity.

\section{Shoot Meristem Maintenance}

The shoot meristem contains a central region of stem cells with reduced division rates which is surrounded by a peripheral zone of more rapidly dividing cells (Fig. 5; Steeves and Sussex, 1989; Meyerowitz 1997a). The stem cells are relatively undifferentiated in the sense that they lack morphological features associated with cells in mature tissues. The CLAVATA (CLVI and CLV3), WIGGUM (WIG), and SHOOT MERISTEMLESS (STM) genes are implicated in regulation of the balance between maintaining the stem cell population and initiation of organ formation (Clark et al., 1996; Running et al., 1998). clv and wig mutants display overproliferation of the central and peripheral zones, respectively, thereby creating an enlarged meristem. These phenotypes implicate the $C L V$ and WIG genes in the control of cell division and/or promoting differentiation leading to organ formation (Clark et al., 1993, 1995, 1997; Running et al., 1998). Double-mutant analysis shows that WIG acts in a separate pathway from the CLV genes (Running et al., 1998). In stm mutants, adventitious meristems form postembryonically but these always terminate after producing fewer organs than usual (Barton and Poethig 1993; Clark et al., 1996; Endrizzi et al., 1996), suggesting a role for the STM gene in maintenance of the meristem by stimulating cell proliferation and/or suppressing differentiation in the central zone. stm clv1 double mutants display intermediate phenotypes (Clark et al., 1996), indicating that STM and CLVI competitively regulate the balance between undifferentiated cells and organ formation; i.e., they do not act in the same pathway. The STM and CLVI genes are first expressed in the de- 
veloping meristem of the globular and heart stage embryo, respectively, and continue to be expressed in the central meristem (Long et al., 1996; Clark et al., 1997; Long and Barton, 1998). STM activity is required for maintenance but not onset of $C L V l$ expression. These results show that the mechanism of shoot meristem maintenance is set up early in development and is essential for proper meristem activity (Long and Barton, 1998).

The $C L V l$ gene encodes a putative leucine-rich repeat containing receptor kinase, suggesting a function in a signaling pathway (Clark et al., 1997). The CLV3 gene that genetically interacts with $C L V 1$ is a candidate for encoding the CLV1 ligand (Clark et al., 1995).

\section{Root Meristem Maintenance}

In the root, new cells are added to files of different cell types by dividing cells in the root meristem. The initial cells at the end points of these files function as stem cells: with each division they set off new cell tiers while one daughter cell retains its position within the meristem (Dolan et al., 1993). In analogy with the shoot meristem, root meristems also contain a group of slowly dividing cells, the quiescent center (QC; Fig. 6). In pickle ( $p k l$ ) mutants the primary root meristem develops into an abnormally thickened and green structure (Ogas et al., 1997). Root tissue carrying the $p k l$ mutation spontaneously regenerates new embryos and plants because it has retained characteristics of embryonic tissue. Expression of this aberrant differentiation state was suppressed by the plant hormone gibberellin. Although genes like $P K L$ but also $R M L 1, A L F 3$, and $H B T$ are required for maintaining root meristem activity, it is not clear whether this reflects their primary function or is a consequence of more general or earlier effects.

In the Arabidop sis root, all stem or initial cells surround and contact the QC (Fig. 6), which consists of only four mitotically inactive cells. Laser ablation of one QC cell results in the cessation of division and the progression of cell differentiation in the underlying columella initial in a contact-dependent manner. The columella initials contacting the neighboring intact QC cell still perform their normal asymmetric division (van den Berg et al., 1997). Cortex initials contacting the ablated QC cell also progress in differentiation status: they behave as daughters and divide asymmetrically. Support for direct suppression of differentiation comes from ablation experiments in mutants that lack postembryonic cell divisions. QC ablation in these mutants also results in differentiation, which is therefore independent on the initial cell's ability to divide (van den Berg et al., 1997). Thus the QC may directly inhibit differentiation of all surrounding initials in a contact-dependent manner, thereby maintaining their stem cell status (Fig. 6). A possibly contact-dependent signaling mechanism is reminiscent of control of differentiation in animal systems by the NOTCH-DELTA receptor-ligand interaction that represses the differentiation of neuroblasts in Drosophila (Muskavitch, 1994; Rooke and Xu, 1998).

When is a differentiation control mechanism set up in the root meristem? As 


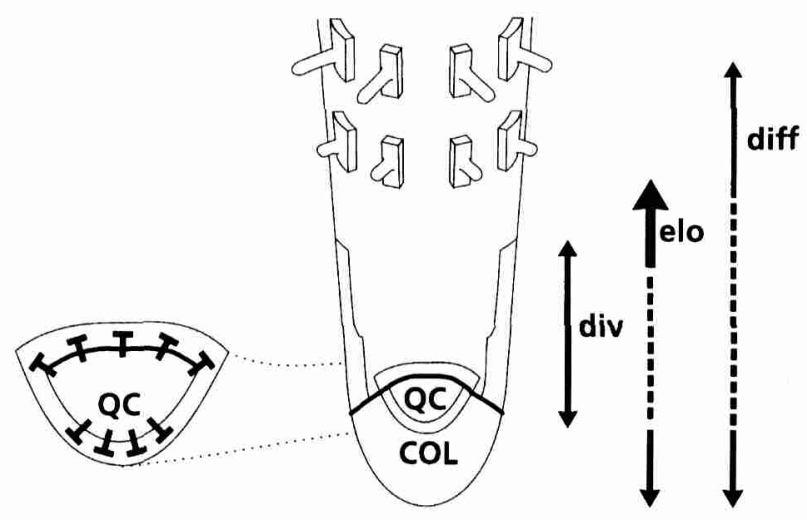

Fig. 6 Cellular activities in root development. The seedling root encompasses three partly overlapping developmental zones (arrows): the division (div), elongation (elo), and differentiation (diff) zones. Arrow thickness indicate elongation rate and terminal differentiation. QC, quiescent center; COL, columella. Detachment: the initial cells of the different cell types surround and contact the QC, which inhibits differentiation, thereby ensuring their stem cell status.

mentioned in Section IIB 1, hbt mutants are affected in the development of the basal domain, resulting in the absence of the $\mathrm{QC}$ by anatomical and functional criteria. The characteristic cell division pattern for initial cells is not observed in $h b t$ embryos; e.g., cells at the position of the cortex initials have already divided asymmetrically, and meristem activity is absent (Willemsen et al., 1998). These observations indicate that the mechanism for maintaining undifferentiated initials in the root meristem is set up during embryogenesis and is essential for meristem activity.

When signals from the QC inhibit differentiation, there may also be signals inducing differentiation. Root initials are not undifferentiated as they can be marked with cell type specific promoter/enhancer traps (van den Berg et al., 1995; Malamy and Benfey, 1997b). Therefore, progression of differentiation is regulated and not the maintenance of a group of undifferentiated cells. Does differentiation require positive input or do cells differentiate by default in a cell-autonomous manner? In the shoot meristem, where STM and $C L V 1$ are implicated in regulating the differentiation status of meristem cells, one interpretation is that STM inhibits and CLV1 activity promotes cell differentiation (Laux and Schoof, 1997). In analogy, recently identified root meristem specific $C L V 1$-like genes (our unpublished data) may be involved in promoting differentiation of root meristem cells once they no longer contact the $\mathrm{QC}$ or once the influence of a QC-derived inhibitory signal is eliminated.

In conclusion, maintaining root and shoot meristem activity may require a balance of signals regulating the differentiation status of the stem cells and their daughters. The $C L V 1$ gene and its root-specific homologues provide tools to test this model. 


\section{Growth and Organ Morphogenesis}

As cells become committed to a developmental fate, they undergo differentiation, which is accompanied by changes in cell size and shape. A recent review extensively discusses the current knowledge on cell morphogenesis-i.e., the acquisition of a particular shape-of different genetically well-characterized cell types in Arabidopsis (Hülskamp et al., 1997). Instead we will concentrate here on organ morphogenesis.

The collective changes in cell number and shape equal the size and shape of the entire organism. Therefore, one can easily imagine cell division and expansion being the driving force behind these processes, especially in plants, where cell movement does not occur.

Traditionally, the regulation of growth and morphogenesis in plants is viewed from two perspectives (Fig. 7; reviewed in Kaplan (1992) and Jacobs (1997)). (i) The organismal theory holds that growth and morphogenesis are driven by the expansion of organs whose constituent cells merely partition the resultant volumes (Fig. 7A). Instead of cell division and expansion being the cause of growth and morphogenesis, they represent the markers of it. This represents a spatial view stating that cell division and expansion are specified by global positional signals. However, we emphasize that these signals may be the result of communication between cells. "Global signaling" may be an emerent property of a short-range cellular communication network. (ii) The cellular theory holds that autonomous division and expansion of cells drive growth and morphogenesis (Fig. 7B). Cells are considered individual entities that together make up the organism. This implies that the time and number of cell divisions and the time and extent of expansion are specified cell-autonomously when a cell is formed. Whichever theory is close to reality, both are intimately coupled with patterning. Pattern formation may determine the amount of signal made or its threshold in a cell, thereby indirectly influencing division, or, alternatively, determine the autonomy of division in a cell.

Whether growth and morphogenesis drive or depend on cell division may be determined by directly interfering with the cell cycle through disruption or manipulation of the function of key regulators, e.g., CDC2 protein kinase. In addition, the influence of developmental and, particularly in plants, environmental factors allows the analysis of the relation between growth and cell division. Alternatively, mutants that uncouple growth or morphogenesis from cell division or expansion are useful for investigating whether these processes directly depend on the precise control of cell division and expansion.

\section{A. Growth Can Be Uncoupled from Cell Division}

Growth is the combined activity of cell expansion and cell production. The rate of cell production has two distinct components: the number of dividing cells and their 


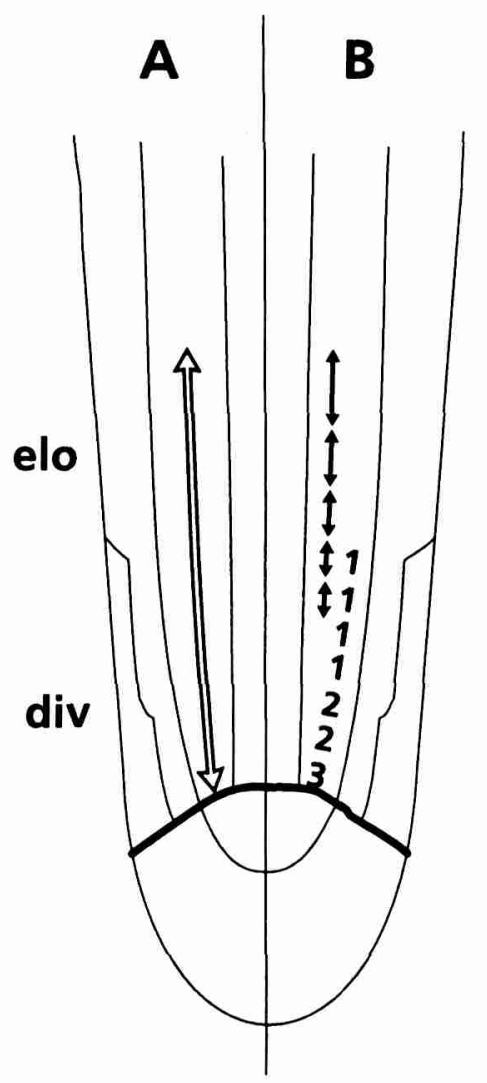

Fig. 7 Mechanisms of growth. (A) Organismal theory. Cells communicate and respond to the total of signaling that determines the position where cells divide and elongate. The arrow represents the outcome of signaling that determines the size of the division and elongation zone. (B) Cellular theory. Division and elongation are cell-autonomous (e.g., counting). Number and arrows represent single cells.

rate of division. An increase in cell production can be caused by an increase in the number of dividing cells or by enhancing the passage through the cell cycle, increasing the division rate, or both. Experiments performed in Drosophila and tobacco in which the function of $\mathrm{CDC} 2$ has been altered allow the analysis of cell division defects on growth.

In the fly, when the last two cell divisions in entire imaginal discs, in anterior compartments, or in clones of cells homozygous for TS-CDC2 are specifically inhibited, wings of normal size are formed (Section IVA; Weigmann et al., 1997). However, the induced mutant wings, compartments, and clones are composed of cells considerably larger than those seen in wild-type controls. Recent experiments 
show that besides lowered cell division, also increased cell division rates has little effect on clone or compartment size of Drosophila wings (Neufeld et al., 1998). These are examples in a series of experiments in different animal systems that show that organ growth control is independent of the exact cell number (Frankhauser, 1941, 1945; Santamaria, 1983; Fero et al., 1996; Kipreos et al., 1996). However, growth is limited in the absence of cell division. In Drosophila, early inactivation of $\mathrm{CDC} 2$ function in the anterior compartment results in a distorted disc shape with few large cells (Weigmann et al., 1997).

In plants, the relation between growth and cell division was examined for the organs of the DN tobacco plants (Section IVA; Hemerly et al., 1995). The introduction of the heterologous $D N-A T C D C 2 A$ slows down but does not completely abolish cell division in tobacco. Developmental timing is not affected, new leaves initiate and grow at the same rate, and mutants flower at the same time. They exhibit slightly smaller organs, and microscopic analysis reveals that cells in all tissues are larger than those from wild type, except in flowers and embryos (Hemerly et al., 1995). The severity of the phenotype in DN plants is directly correlated with the levels of the mutant protein, indicating that titration of regulatory factors reduces the frequency of cell division. In agreement with the experiments in flies, the observation that DN plants are smaller supports the notion that cells cannot grow indefinitely. Nevertheless, experiments in both systems show that when cell division rate is altered, cells compensate for this defect by growing in size so that the overall size of the organs is relatively normal. Taken together, the picture emerges that normal organ size can be reached independent of the exact cell number, consistent with an organismal theory on growth.

\section{Root Growth and Meristem Size Can Be Uncoupled from Cell Division Control}

How do plants modify their growth rate during their postembryogenic development? The observation that the primary roots of plants grow more rapidly with time (Baskin et al., 1995) has been exploited to achieve insight into this question. The seedling root can be divided into three partly overlapping developmental regions: the division zone (meristem), the elongation zone, and the differentiation zone (Fig. 6). The meristem encompasses part of the elongation zone as cell division continues well beyond the location where cell elongation rates start to increase (Dolan and Roberts, 1995b; Jacobs, 1997; Beemster and Baskin, 1998). Differentiation occurs gradually throughout the different developmental zones.

Both cell expansion and cell production have been quantified for cortical cells in growing Arabidopsis roots with a kinematic method, using time-lapse video imaging (Beemster and Baskin, 1998). The acceleration of root growth with time correlates with an increased cell number in the meristem with little change in cellular expansion rate or cell length. This is reflected by an increase in the length of the division and elongation zones and a steady increase of cell numbers in these zones. However, the average cell division rates are approximately constant 
throughout the meristem and remain constant with time (Beemster and Baskin, 1998). The developmentally enhanced growth is compatible with the cellular theory on growth. Namely, a longer competence of a meristematic cell to divide will enhance the number of dividing cells and lead to an enlarging cell division zone. Concomitantly, more cells will be expanding at a given time, increasing also the size of the expansion zone. However, the data can also be explained using the organismal theory: global positional signals allowing cell division may cover an increasing distance over the course of development. As elongation rates and final cell sizes are only slightly altered, the elongation zone has to be similarly extended to allow all cells to reach their normal mature size. Therefore, the sizes of the division and elongation zones should be coupled.

The redox experiments, whereby environmental conditions are simulated by alteration of GSH levels, show that root growth is not or only slightly affected by the decreased or increased cell divisions. Obviously, an increase in cell division results in a decrease of mature cell size and vice versa (Section IVC2a; SanchezFernandez et al., 1997). These results indicate that the size of the division and elongation zones is determined. This way, alterations in rates of cell division will lead to more smaller or fewer larger cells in the division zone but these cells will not reach their normal size because they elongate either too little or too much due to the unaltered elongation zone. Interestingly, regulation of root growth in this way is used by the plant to its own advantage. Addition of GSH produces short hair cells with long hairs, whereas depletion of GSH leads to long hair cells with short or no hairs (Sanchez-Fernandez et al., 1997). In nature, this response allows the root to maintain normal growth and explore the soil under adverse conditions with minimal cell divisions and root hair production or capitalize on a favorable local environment by production of numerous long root hairs.

Together, the foregoing results support the hypothesis that the division and elongation zones are coupled and may actually constitute one developmental zone. This suggests that the signals regulating the sizes of the division and elongation zones are coupled. For example, they may constitute a graded version of one signal or two opposing signals, acting over a distance or by means of coupled shortrange interactions.

\section{B. Organ Morphogenesis Can Be Uncoupled from Cell Division}

Although animal cells can migrate and in this way aid in creating organ shape, plant cells cannot and an invariable sequence of cell division and expansion has often been considered crucial for morphogenesis. Nevertheless, early studies in which cell division was arrested chemically or by irradiation already demonstrated that leafs can initiate and that existing leaves undergo properly oriented, albeit limited, growth in the absence of cell division (Haber, 1962; Haber and Foard, 1963). What is striking in the examples manipulating the cell cycle in tobacco and Drosophila is that a normal shape of the organs is maintained when cell division 
is inhibited, supporting the notion that within a certain range, cell number is not crucial for morphogenesis.

Moreover, mutants obtained in maize in which cell division orientation or cell expansion is affected do not affect organ shape. In mutant tangled-1 (tan-1) leaves of corn, the majority of longitudinal divisions, normally correlated with leaf widening, are substituted by aberrantly oriented divisions (Smith et al., 1996). Other organs are similarly affected, showing that TAN-1 functions throughout the plant in controlling the orientation of cell division. Although mutant leaves grow more slowly and their final size is smaller than normal, their shapes at all stages of leaf growth are similar to those of normal leaves of the same length. In the warty-1 (wty-1) mutant, mature leaves have raised warts that appear in patchy distribution, consisting of excessively enlarged cells, but cell sizes are also abnormal in internal leaf tissues (Reynolds et al., 1998). The primary mutant defect is overexpansion of cells. When the cells are enlarged more than $133 \%$ relative to nonmutant cells, they perform abnormally oriented and incomplete cell divisions. Cells adjoining these abnormally enlarged cells in wty- 1 mutants divide more rapidly and expand less than comparably positioned cells in wild-type plants. Despite these defects, wty-l mutant leaves are normal in size and shape, showing that the cell expansion defects are compensated by neighboring cells.

In conclusion, these results demonstrate that organ morphogenesis is relatively independent of the precise control of cell division rate and, at least in plants, cell division orientation and cell expansion. Therefore, it follows that morphogenesis is regulated at the supracellular level, either by a separate category of signals or by a cellular communication network.

\section{What Are the Molecules Involved in Determining Organ Size and Shape?}

To identify growth determinants requires compounds to be able to alter organ sizes due to more or less incorporated cells, without affecting cell division or elongation characteristics. They would have to act in a concentration-dependent manner and may originate from and affect communicating cells. A candidate for such a growth agent in animals is nitric oxide (NO), which may be involved in controlling the size of body structures during Drosophila development (Kuzin et al., 1996). NO is a diffusible multifunctional second messenger that has been implicated in numerous physiological functions in animals (Schmidt and Walter, 1994). In addition, NO can act in cells as an efficient antiproliferative agent (Garg and Hassid, 1989; Chen et al., 1998). In flies, NO synthase (NOS) is expressed at high levels in developing imaginal discs. Inhibition of NOS in larvae causes an increase in size of some organs in adult flies, corresponding to an increase in cell number, whereas ectopic expression of NOS has the opposite effect (Kuzin et al., 1996). Interestingly, in the developing leg, the segments that are most affected by NOS 
inhibition and ectopic induction corresponded to those that normally have high and low expression of NOS, respectively. This suggests that NO may play a causative role in growth arrest in normal development. In addition, the pattern of NOS expression correlates with the growth capacity of the particular segment, indicating that pattern formation and growth are normally coordinated.

In plants, the embryos, leafs, and flowers grow to a particular size. In shoots the size of the meristem is important for the formation of correct organ numbers, and in roots the size of the meristematic and elongation zone needs to be determined to regulate the growth rate. Compounds that would qualify for a growth determinant, analogous to NO, remain to be identified in plants. However, this growth determinant may be a composition of more integrated intercellular signals directing rate and orientation of division and elongation. Mutations in one signaling pathway can be compensated for by adjusting the other processes, but only up to a certain level. Accordingly, in animals and plants, growth and cell division can be uncoupled but when cell division is severely inhibited, growth is affected.

\section{Concluding Remarks}

After the first decade of intense investigation of plant development by molecular genetic approaches, the mechanisms of axis formation and pattern formation are still uncertain and it cannot yet be decided whether they will differ significantly from mechanisms used outside the plant kingdom. The identification of only a low number of genes involved in these processes, despite large-scale screening efforts, can be explained by embryo lethality and by extensive genetic redundancy. For the latter case, some evidence has emerged. The generation of a large collection of gene/enhancer traps in combination with the rapid progress of the Arabidopsis genome project should change this situation in the future.

The scarce knowledge on axis formation in the plant embryo, assembled with the help of complementary studies in the brown alga Fucus, hint at the importance of localized cues in the cell wall. The nature of the cues is unknown, and the mechanisms involved may turn out to bear resemblance to asymmetry-generating mechanisms in yeast (Chant, 1994, 1996), nematodes (Guo and Kemphues, 1996), or flies (Yan and Yan, 1998) as these all involve localized cues in the cell cortex. Although all these organisms utilize mobilization of the cytoskeleton to a localized cue, the mechanisms seem to differ considerably in the genes that are deployed, so a novel variant in plants may be expected. Molecular genetic dissection of embryo pattern formation has not yet established rigorous concepts, in part because the mutants that have been analyzed do not allow the straightforward deduction of underlying mechanisms. The genes that have, however, been identified, some of which are required at an early stage, will undoubtedly serve as an aid to bootstrap researches into the regulatory mechanisms of early patterning.

The ongoing process of patterning in meristems, one of the most fascinating as- 
pects of plant development, is receiving increasing attention. The Arabidopsis root meristem is suited to investigate the continuous signaling events that facilitate the flexible acquisition of cell fate and their relation to embryo patterning. Molecular genetic analysis of the shoot meristem is providing important clues on how meristems maintain themselves by regulating the balance between cell differentiation and cell division, and the emerging information can be utilized to study similar questions in the root meristem. The availability of genes involved in cell division and the potential to study their function in transgenic plants are a second avenue that is actively pursued by plant scientists to understand meristems, and major progress can be expected in the near future.

The role of cell division in plant development, previously almost unanimously considered important for patterning, growth, and morphogenesis, is beginning to be critically questioned, as plants and animals turn out be astonishingly alike in their capacity to regulate perturbations in cell division rate and orientation.

The limited complexity of the plant body bears the inherent promise that, despite a slow start compared to the animal model systems, valuable knowledge can be gained in plants on the interaction of different aspects of multicellular development (Meyerowitz, 1997a). When we have some insight into this interplay, we can start to understand at a deeper level the perhaps most remarkable aspect of plant development: its flexibility and its continuous ability to respond to the environment.

\section{References}

Aida, M., Ishida, T., Fukaki, H., Fujisawa, H., and Tasaka, M. (1997). Genes involved in organ separation in Arabidopsis: An analysis of the cup-shaped cotyledon mutant. Plant Cell 9, 841-857.

Babiychuk, E., Kushnir, S., Belles-Boix, E., Van Montagu, M., and Inzé, D. (1995). Arabidopsis thaliana NADPH oxidoreductase homologs confer tolerance of yeasts toward the thiol-oxidizing drug diamide. J. Biol. Chem. 270, 26224-26231.

Barton, M. K., and Poethig, R. S. (1993). Formation of the shoot apical meristem in Arabidopsis thaliana: An analysis of development of the wild type in the shoot meristemless mutant. Development 119, 823-831.

Baskin, T. I., Cork, A., Williamson, R. E., and Gorst, R. (1995). STUNTED PLANT1, a gene required for expansion in rapidly elongating but not in dividing cells and mediating root growth responses to applied cytokinin. Plant Physiol. 107, 233-243.

Basler, K., and Struhl, G. (1994). Compartment boundaries and the control of Drosophila limb pattern by hedgehog protein. Nature 368, 208-214.

Beemster, G. T., and Baskin, T. I. (1998). Analysis of cell division and elongation underlying the developmental acceleration of root growth in Arabidopsis thaliana. Plant Physiol. 116, 1515-1526.

Benfey, P., Linstead, P., Roberts, K., Schiefelbein, J., Hauser, M.-T., and Aeschbacher, R. (1993). Root development in Arabidopsis: Four mutants with dramatically altered root morphogenesis. Development 119, 57-70.

Berger, F., Taylor, A., and Brownlee, C. (1994). Cell fate determination by the cell wall in early Fucus development. Science 263, 1421-1423.

Berger, F., Haselhoff, J., Schiefelbein, J., and Dolan, L. (1998a). Positional information in root epi- 
dermis is defined during embryogenesis and acts in domains with strict boundaries. Curr. Biol. 17, 421-430.

Berger, F., Hung, C. Y., Dolan, L., and Schiefelbein, J. (1998b). Control of cell division in the root epidermis of Arabidopsis thaliana. Dev. Biol. 194, 235-245.

Berleth, T., and Jürgens, G. (1993). The role of the monopteros gene in organising the basal body region of the Arabidopsis embryo. Development 118, 575-587.

Berleth, T., Hardtke, C. S., Przemeck, G. K. H., and Müller, J. (1996). Mutational analysis of root initiation in the Arabidopsis embryo. Plant Soil 187, 1-9.

Bowler, C., Van Montagu, M., and Inzé, D. (1992). Superoxide dismutase and stress tolerance. Annu. Rev. Plant Physiol. Plant Mol. Biol. 43, 83-116.

Bruck, D. K., and Walker, D. B. (1985). Cell determination during embryogenesis in Citrus jambhiri. I. Ontogeny of the epidermis. Bot. Gaz. 146, 188-195.

Bush, M., Mayer, U., and Jürgens, G. (1996). Molecular analysis of the Arabidopsis pattern formation gene GNOM: Gene structure and intragenic complementation. Mol. Gen. Genet. 250, 681691.

Carnac, G., and Gurdon, J. B. (1997). The community effect in Xenopus myogenesis is promoted by dorsalizing factors. Int. J. Dev. Biol. 41, 521-524.

Celenza, J. L., Jr., Grisafi, P. L., and Fink, G. R. (1995). A pathway for lateral root formation in Arabidopsis thaliana. Genes Dev. 9, 2131-2142.

Chant, J. (1994). Cell polarity in yeast. Trends Genet. 10, 328-333.

Chant, J. (1996). Septin scaffolds and cleavage planes in Saccharomyces. Cell 84, 187-190.

Chen, L., Daum, G., Forough, R., Clowes, M., Walter, U., and Clowes, A. W. (1998). Overexpression of human endothelial nitric oxide synthase in rat vascular smooth muscle cells and in balloon-injured carotid artery. Circ. Res. 82, 862-870.

Cheng, J. C., Seeley, K. A., and Sung, Z. R. (1995). RML1 and RML2, Arabidopsis genes required for cell proliferation at the root tip. Plant Physiol. 107, 365-376.

Citterio, S., Sgorbati, S., Scrippa, S., and Sparvoli, E. (1994). Ascorbic acid effect on the onset of cell proliferation in pea root. Physiol. Plant. 92, 601-607.

Clark, S. E. (1997). Organ formation at the vegetative shoot meristem. Plant Cell 9 (Special Issue), 1067-1076.

Clark, S. E., Running, M. P., and Meyerowitz, E. M. (1993). CLAVATAI, a regulator of meristem and development in Arabidopsis. Development 119, 397-418.

Clark, S. E., Running, M. P., and Meyerowitz, E. M. (1995). CLAVATA3 is a specific regulator of shoot and floral meristem development affecting the same processes as CLAVATA1. Development 121, 2057-2067.

Clark, S. E., Jacobsen, S. E., Levin, J. Z., and Meyerowitz, E. M. (1996). The CLAVATA and SHOOT MERISTEMLESS loci competitively regulate meristem activity in Arabidopsis. Development 122 , 1567-1575.

Clark, S. E., Williams, R. W., and Meyerowitz, E. M. (1997). The CLAVATAl gene encodes a putative receptor kinase that controls shoot and floral meristem size in Arabidopsis. Cell 89, 575585.

Clowes, F. A. L. (1975). The quiescent centre. In "The Development and Function of Roots" (J. G. Torrey and D. T. Clarkson, Eds.), pp. 3-19. Academic Press, New York.

Cohen, S. M. (1996). Controlling growth of the wing: Vestigial integrates signals from the compartment boundaries. BioEssays 18, 855-858.

Conklin, P. L., Williams, E. H., and Last, R. L. (1996). Environmental stress sensitivity of an ascorbic acid-deficient Arabidopsis mutant. Proc. Natl. Acad. Sci. USA 93, 9970-9974.

Di Christina, M. D., Sessa, G., Dolan, L., Linstead, P., Baima, S., Ruberti, I., and Morelli, G. (1996). The Arabidopsis Athb-10 (GLABRA2) is an HD-Zip protein required for regulation of root hair development. Plant J. 10, 393-402.

Di Laurenzio, L., Wysockadiller, J., Malamy, J. E., Pysh, L., Helariutta, Y., Freshour, G., Hahn, 
M. G., Feldmann, K. A., and Benfey, P. N. (1996). The SCARECROW gene regulates an asymmetric cell division that is essential for generating the radial organization of the Arabidopsis root. Cell 86, 423-433.

Dolan, L., and Roberts, K. (1995a). Two ways to skin a plant: The analysis of root and shoot epidermal development in Arabidopsis. BioEssays 17, 865-872.

Dolan, L., and Roberts, K. (1995b). Plant development: Pulled up by the roots. Curr. Opin. Genet. Dev. 5, 432-438.

Dolan, L., Janmaat, K., Willemsen, V., Linstead, P., Poethig, S., Roberts, K., and Scheres, B. (1993). Cellular organisation of the Arabidopsis root. Development 119, 71-84.

Dolan, L., Duckett, C. M., Grierson, C., Linstead, P., Schneider, K., Lawson, E., Dean, C., Poethig, S., and Roberts, K. (1994). Clonal relationships and cell patterning in the root epidermis of Arabidopsis. Development 120, 2465-2474.

Drews, G. N., Lee, D., and Christensen, C. A. (1998). Genetic analysis of female gametophyte development and function. Plant Cell 10,5-17.

Duckett, C., Oparka, K., Prior, D., Dolan, L., and Roberts, K. (1994). Dye-coupling in the root epidermis of Arabidopsis is progressively reduced during development. Development 120, 32473255 .

Ecker, J. (1995). The ethylene signal transduction pathway in plants. Science 268, 667-675.

Edgar, B. A., Lehman, D. A., and O'Farrell, P. H. (1994). Transcriptional regulation of string $(c d c 25)$ : A link between developmental programming and the cell cycle. Development 120, 3131-3143.

Endrizzi, K., Moussian, B., Haecker, A., Levin, J. Z., and Laux, T. (1996). The SHOOT MERISTEMLESS gene is required for maintenance of undifferentiated cells in Arabidopsis shoot and floral meristems and acts at a different regulatory level than the meristem genes WUSCHEL and ZWILLE. Plant J. 10, 967-979.

Evans, T., Crittenden, S., Kodoyianni, V., and Kimble, J. (1994). Translational control of $g l p-1$ mRNA establishes an asymmetry in the C. elegans embryo. Cell 77, 183-194.

Fero, M. L., Rivkin, M., Tasch, M., Porter, P., Carow, C. E., Firpo, E., Polyak, K., Tsai, L. H., Broudy, V., Perlmutter, R. M., Kaushansky, K., and Roberts, J. M. (1996). A syndrome of multiorgan hyperplasia with features of gigantism, tumorigenesis, and female sterility in p27(Kipl)-deficient mice. Cell 85, 733-744.

Fluhr, R. (1998). Ethylene perception: From two-component signal transducers to gene induction. Trends Plant Sci. 3, 141-146.

Folette, P. J., and O'Farrell, P. H. (1997). Connecting cell behaviour to patterning: Lessons from the cell cycle. Cell 88, 309-314.

Frankhauser, G. (1941). Cell size, organ and body size in triploid newts (Triturus viridescens). J. Morphol. 68, 161-177.

Frankhauser, G. (1945). Maintenance of normal structure in heteroploid salamander larvae, through compensation of changes in cell size by adjustment of cell number and cell shape. J. Exp. Zool. 100, 445-455.

Fukaki, H., Wysocka-Diller, J., Kato, T., Fujisawa, H., Benfey, P. N., and Tasaka, M. (1998). The endodermis is essential for shoot gravitropism in Arabidopsis thaliana. Plant J. 14, 425-430.

Furner, I. J., and Pumfrey, J. E. (1992). Cell fate in the shoot apical meristem of Arabidopsis thaliana. Development 115, 755-764.

Galway, M. E., Masucci, J. D., Lloyd, A. M., Walbot, V., Davis, R. W., and Schiefelbein, J. W. (1994). The $T T G$ gene is required to specify epidermal cell fate and cell patterning in the Arabidopsis root. Dev. Biol. 166, 740-754.

Garg, U. C., and Hassid, A. (1989). Inhibition of rat mesangial cell mitogenesis by nitric oxide-generating vasodilators. Am. J. Physiol. 257, F60-F66.

Gomez-Skarmeta, J. L., del Corral, R. D., de la Calle-Mustienes, E., Ferres-Marco, D., and Modolell, J. (1996). araucan and caupolican, two members of the novel iroquois complex, encode homeoproteins that control proneural and vein-forming genes. Cell 85, 95-105. 
Grierson, C. S., Roberts, K., Feldmann, K. A., and Dolan, L. (1997). The COWl locus of Arabidopsis acts after RHD2, and in parallel with RHD3 and TIP1, to determine the shape, rate of elongation, and number of root hairs produced from each site of hair formation. Plant Physiol. 115, 981-990.

Grossniklaus, U., Vielle-Calzada, J. P., Hoeppner, M. A., and Gagliano, W. B. (1998). Maternal control of embryogenesis by MEDEA, a Polycomb group gene in Arabidopsis. Science 280, 446-450.

Guo, S., and Kemphues, K. J. (1996). Molecular genetics of asymmetric cleavage in the early Caenorhabditis elegans embryo. Curr. Opin. Genet. Dev. 6, 408-415.

Gurdon, J. B. (1992). The generation of diversity and pattern in animal development. Cell 68, 185199.

Gurdon, J. B., Tiller, E., Roberts, J., and Kato, K. (1993). A community effect in muscle development. Curr. Biol. 3, 1-11.

Haber, A. H. (1962). Nonessentiality of concurrent cell divisions for degree of polarization of leaf growth. I. Studies with radiation-induced mitotic inhibition. Am. J. Bot. 49, 583-589.

Haber, A. H., and Foard, D. E. (1963). Nonessentiality of concurrent cell divisions for degree of polarization of leaf growth. II. Evidence from untreated plants and from chemically induced changes of the degree of polarization. Am. J. Bot. 50, 937-944.

Hardtke, C. S., and Berleth, T. (1998). The Arabidopsis gene MONOPTEROS encodes a transcription factor mediating embryo axis formation and vascular development. EMBO J. 17, 14051411.

Hemerly, A., de Almeida Engler, J., Bergounioux, C., Van Montagu, M., Engler, G., Inzé, D., and Ferreira, P. (1995). Dominant negative mutants of the $C d c 2$ kinase uncouple cell division from iterative plant development. EMBO J. 14, 3925-3936.

Hülskamp, M., Misera, S., and Jürgens, G. (1994). Genetic dissection of trichome cell development in Arabidopsis. Cell 76, 555-566.

Hülskamp, M., Folkers, U., and Grini, P. E. (1997). Cell morphogenesis in Arabidopsis. BioEssays 20, 20-29.

Irish, V. E., and Sussex, I. M. (1992). A fate map of the Arabidopsis embryonic shoot apical meristem. Development 115, 745-753.

Jackson, D., Veit, B., and Hake, S. (1994). Expression of maize KNOTTEDl related homeobox genes in the shoot apical meristem predicts patterns of morphogenesis in the vegetative shoot. Development 120, 405-413.

Jacobs, T. (1997). Why do plant cells divide? Plant Cell 9 (Special Issue), 1021-1029.

Jürgens, G. (1995). Axis formation in plant embryogenesis: Cues and clues. Cell 81, 467-470.

Jürgens, G. (1996). Cell division and morphogenesis in angiosperm embryogenesis. Semin. Cell Dev. Biol. 7, 867-872.

Jürgens, G., and Mayer, U. (1994). Arabidopsis. In "EMBRYOS. Colour Atlas of Development" (J. Bard, Ed.), pp. 7-21. Wolfe Publications, London.

Jürgens, G., Grebe, M., and Steinmann, T. (1997). Establishment of cell polarity during early plant development. Curr. Opin. Cell Biol. 9, 849-852.

Kaplan, D. R. (1992). The relationship of cells to organisms in plants: Problem and implications of an organismal perspective. Int. J. Plant Sci. 153, S28-S37.

Kaplan, D. R., and Cooke, T. J. (1997). Fundamental concepts in the embryogenesis of dicotyledons: A morphological interpretation of embryo mutants. Plant Cell 9, 1903-1919.

Kehl, B. T., Cho, K. O., and Choi, K. W. (1998). mirror, a Drosophila homeobox gene in the Iroquois complex, is required for sensory organ and alula formation. Development 125, 1217-1227.

Kerk, N. M., and Feldman, L. J. (1995). A biochemical model for the initiation and maintenance of the quiescent centre; implications for organization of root meristems. Development 121, 28252833.

Kerstetter, R. A., Laudencia-Chingcuanco, D., Smith, L. G., and Hake, S. (1997). Loss-of-function mutations in the maize homeobox gene, knottedl, are defective in shoot meristem maintenance. Development 124, 3045-3054. 
Kim, J., Sebring, A., Esch, J. J., Kraus, M. E., Vorwerk, K., Magee, J., and Carroll, S. B. (1996). Integration of positional signals and regulation of wing formation and identity by the Drosophila vestigial gene. Nature 382, 133-138.

Kipreos, E. T., Lander, L. E., Wing, J. P., He, W. W., and Hedgecock, E. M. (1996). cul-1 is required for cell cycle exit in C. elegans and identifies a novel gene family. Cell 85, 829-839.

Kropf, D. L., Kloareg, B., and Quatrano, R. S. (1988). Cell wall is required for fixation of the embryonic axis in Fucus zygotes. Science 239, 187-190.

Kuzin, B., Roberts, I., Peunova, N., and Enikolopov, G. (1996). Nitric oxide regulates cell proliferation during Drosophila development. Cell 87, 639-649.

Lauber, M. H., Waizenegger, I., Steinmann, T., Schwarz, H., Mayer, U., Hwang, I., Lukowitz, W., and Jürgens, G. (1997). The Arabidopsis KNOLLE protein is a cytokinesis-specific syntaxin. J. Cell Biol. 139, 1485-1493.

Laux, T., and Jürgens, G. (1997). Embryogenesis: A new start in life. Plant Cell 9, 989-1000.

Laux, T., and Mayer, K. F. (1998). Cell fate regulation in the shoot meristem. Semin. Cell. Dev. Biol. 9, 195-200.

Laux, T., and Schoof, H. (1997). Maintaining the root meristem-The role of CLAVATA1. Trends Plant Sci. 2, 325-327.

Lee, J. J., von Kessler, D. P., Parks, S., and Beachy, P. A. (1992). Secretion and localized transport suggests a role in positional signaling for products of the segmentation gene hedgehog. Cell 71, $33-50$.

Liso, B. R., Calabrese, G., Bitoni, M. B., and Arrigoni, O. (1984). Relationship between ascorbic acid and cell division. Exp. Cell Res. 150, 314-320.

Liso, B. R., Innocenti, A. M., Bitoni, M. B., and Arrigoni, O. (1988). Ascorbic acid induced progression of quiescent centre cells from G1 to S phase. New Phytol. 110, 469-471.

Lloyd, A. M., Schena, M., Walbot, V., and Davis, R. W. (1994). Epidermal cell fate determination in Arabidopsis: Patterns defined by steroid-inducible regulator. Science 266, 436-439.

Long, J. A., and Barton, K. (1998). The development of embryonic pattern in Arabidopsis. Development 126, 3027-3035.

Long, J. A., Moan, E. I., Medford, J. I., and Barton, M. K. (1996). A member of the KNOTTED class of homeodomain proteins encoded by the STM gene of Arabidopsis. Nature 379, 66-69.

Lu, P., Porat, R., Nadeau, J., and O'Neill, S. (1996). Identification of a meristem L1 layer specific gene in Arabidopsis that is expressed during embryonic pattern formation and defines a new class of homeobox genes. Plant Cell 8, 2155-2168.

Lucas, W. J., Bouche-Pillon, S., Jackson, D. P., Nguyen, L., Baker, L., Ding, B., and Hake, S. (1995). Selective trafficking of KNOTTED1 homeodomain protein and its mRNA through plasmodesmata. Science 270, 1980-1983.

Lukowitz, W., Mayer, U., and Jürgens, G. (1996). Cytokinesis in the Arabidopsis embryo involves the syntaxin-related KNOLLE gene product. Cell 84, 61-71.

Malamy, J. E., and Benfey, P. N. (1997a). Down and out in Arabidopsis: The formation of lateral roots. Trends Plant Sci. 2, 390-396.

Malamy, J., and Benfey, P. N. (1997b). Organization and cell differentiation in lateral roots of Arabidopsis thaliana. Development 124, 33-44.

Mansfield, S., and Briarty, L. (1991). Early embryogenesis in Arabidopsis thaliana. II. The developing embryo. Can. J. Bot. 69, 461-467.

Masucci, J. D., and Schiefelbein, J. (1994). The rhd6 mutation of Arabidopsis thaliana alters roothair initiation through an auxin- and ethylene-associated process. Plant Physiol. 106, 1335-1346.

Masucci, J. D., and Schiefelbein, J. W. (1996). Hormones äct downstream of $T T G$ and $G L 2$ to promote root hair outgrowth during epidermis development in the Arabidopsis root. Plant Cell 5, 1505-1517.

Masucci, J. D., Rerie, W. G., Foreman, D. R., Zhang, M., Galway, M. E., Marks, M. D., and Schiefelbein, J. W. (1996). The homeobox gene GLABRA 2 is required for position-dependent cell differentiation in the root epidermis of Arabidopsis thaliana. Development 122, 1253-1260. 
May, M. J., and Leaver, C. J. (1993). Oxidative stimulation of glutathione synthesis in Arabidopsis thaliana suspension cultures. Plant Physiol. 103, 621-627.

Mayer, U., Torres-Ruiz, R., Berleth, T., Misera, S., and Jürgens, G. (1991). Mutations affecting body organization in the Arabidopsis embryo. Nature 353, 402-407.

Mayer, U., Büttner, G., and Jürgens, G. (1993). Apical-basal pattern formation in the Arabidopsis embryo: Studies on the role of the gnom gene. Development 117, 149-162.

McLean, B. G., Hempel, F. D., and Zambryski, C. (1997). Plant intercellular communication via plasmodesmata. Plant Cell 9, 1043-1054.

Meinke, D. W. (1986). Embryo-lethal mutants and the study of plant embryo development. Oxf. Surv. Plant Mol. Cell Biol. 3, 122-165.

Meyerowitz, E. M. (1997a). Genetic control of cell division patterns in developing plants. Cell 88, 299-308.

Meyerowitz, E. M. (1997b). Plants and the logic of development. Genetics 145, 5-9.

Mordhorst, A. P., Toonen, M. A. J., and de Vries, S. C. (1997). Plant embryogenesis. Crit. Rev. Plant Sci. 16, 535-576.

Mossessova, E., Gulbis, J. M., and Goldberg, J. (1998). Structure of the guanine nucleotide exchange factor Sec7 domain of human Arno and analysis of the interaction with ARF GTPase. Cell 92 , 415-423.

Muskavitch, M. A. T. (1994). Delta-Notch signaling and Drosophila cell fate choice. Dev. Biol. 166, 415-430.

Neufeld, T. P., de la Cruz, A. F., Johnston, L. A., and Edgar, B. A. (1998). Coordination of growth and cell division in the Drosophila wing. Cell 93, 1183-1193.

Ogas, J., Cheng, J. C., Sung, Z. R., and Somerville, C. (1997). Cellular differentiation regulated by gibberellin in the Arabidopsis thaliana pickle mutant. Science 277, 91-94.

Oparka, K. J., Duckett, C. M., Prior, D. A. M., and Fischer, D. B. (1994). Real-time imaging of phloem unloading in the root tip of Arabidopsis. Plant J. 6, 759-766.

Oppenheimer, D. G., Herman, P. L., Sivakumaran, S., Esch, J., and Marks, M. D. (1991). A myb gene required for leaf trichome differentiation in Arabidopsis is expressed in stipules. Cell 67, 483493.

Parcy, F., Nilsson, O., Busch, M. A., Lee, I., and Weigel, D. (1998). A genetic framework for floral patterning. Nature 395, 561-566.

Peyroche, A., Paris, S., and Jackson, C. L. (1996). Nucleotide exchange on ARF mediated by yeast Geal protein. Nature 384, 479-484.

Pollock, E. G., and Jensen, W. A. (1964). Cell development during early embryogenesis in Capsella and Gossypium. Am. J. Bot. 51, 915-921.

Poot, M., Teubert, H., Rabinovitch, P. S., and Kavanagh, T. J. (1995). De novo synthesis of glutathione is required for both entry into and progression through the cell cycle. J. Cell Physiol. $163,555-560$.

Priess, J., Schnabel, H., and Schnabel, R. (1987). The $g l p-1$ locus and cellular interactions in early $C$. elegans embryos. Cell 51, 601-611.

Przemeck, G. K. H., Mattsson, J., Hardtke, C. S., Sung, Z. R., and Berleth, T. (1996). Studies on the role of the Arabidopsis gene MONOPTEROS in vascular development and plant cell axialization. Planta 200, 229-237.

Rerie, W. G., Feldmann, K. A., and Marks, M. D. (1994). The GLABRA2 gene encodes a homeodomain protein required for normal trichome development in Arabidopsis. Genes Dev. 8, 1388 1399.

Reynolds, J. O., Eisses, J. F., and Sylvester, A. W. (1998). Balancing division and expansion during maize leaf morphogenesis: Analysis of the mutant, warty-1. Development 125, 259-268.

Rooke, J. E., and Xu, T. (1998). Positive and negative signals between interacting cells for establishing neural fate. BioEssays 20, 209-214.

Running, M. P., Fletcher, J. C., and Meyerowitz, E. M. (1998). The WIGGUM gene is required for proper regulation of floral meristem size in Arabidopsis. Development 125, 2545-2553. 
Russo, T., Zambrano, N., Esposito, F., Ammendola, R., Cimino, F., Fiscella, M., Jackman, J., O'Connor, P. M., Anderson, C. W., and Appella, E. (1995). A p53-independent pathway for activation of WAFl/CIP1 expression following oxidative stress. J. Biol. Chem. 270, 29386-29391.

Sachs, T. (1991). Cell polarity and tissue patterning in plants. Development. Suppl. 1, 83-93.

Sánchez-Fernández, R., Fricker, M., Corben, L. B., White, N. S., Sheard, N., Leaver, C. J., Van Montagu, M., Inzé, D., and May, M. J. (1997). Cell proliferation and root hair tip growth in the Arabidopsis root are under mechanistically different forms of redox control. Proc. Natl. Acad. Sci. USA 94, 2745-2750.

Santamaria, P. (1983). Analysis of haploid mosaics in Drosophila. Dev. Biol. 9, 285-295.

Scheres, B., and Wolkenfelt, H. (1998). The Arabidopsis root as a model to study plant development. Plant Physiol. Biochem. 36, 21-32.

Scheres, B., Wolkenfelt, H., Willemsen, V., Terlouw, M., Lawson, E., Dean, C., and Weisbeek, P. (1994). Embryonic origin of the Arabidopsis primary root and root meristem initials. Development 120, 2475-2487.

Scheres, B., Di Laurenzio, L., Willemsen, V., Hauser, M. T., Janmaat, K., Weisbeek, P., and Benfey, P. N. (1995). Mutations affecting the radial organisation of the Arabidopsis root display specific defects throughout the embryonic axis. Development 121, 53-62.

Scheres, B., McKhan, H. I., and van den Berg, C. (1996). Roots redefined: Anatomical and genetic analysis of root development. Plant Physiol. 111, 959-964.

Schiefelbein, J., Masucci, J. D., and Wang, H. (1997). Building a root: The control of patterning and morphogenesis during root development. Plant Cell 9 (Special Issue), 1089-1098.

Schmidt, H. H. W., and Walter, U. (1994). NO at work. Cell 78, 919-925.

Schnabel, R. (1996). Pattern formation: Regional specification in the early C. elegans embryo. BioEssays 18, 591-594.

Schnittger, A., Grini, P. E., Folkers, U., and Hülskamp, M. (1996). Epidermal fate map of the Arabidopsis shoot meristem. Dev. Biol. 175, 248-255.

Schnittger, A., Jürgens, G., and Hülskamp, M. (1998). Tissue layer and organ specificity of trichome formation are regulated by GLABRAI and TRIPTYCHON in Arabidopsis. Development 125, 2283-2289.

Shaw, S. L., and Quatrano, R. S. (1996). The role of targeted secretion in the establishment of cell polarity and orientation of the division plane in Fucus zygotes. Development 122, 2623-2630.

Shevell, D., Leu, W.-M., Stewart Gillmor, S., Xia, G., Feldmann, K., and Chua, N.-H. (1994). ЕМВОЗО is essential for normal cell division, cell expansion, and cell adhesion in Arabidopsis and encodes a protein that has similarity to Sec7. Cell 77, 1051-1062.

Sinha, N. R., Williams, R. E., and Hake, S. (1993). Overexpression of the maize homeobox gene, KNOTTED-1, causes a switch from determinate to indeterminate cell fates. Genes Dev. 7, 787795.

Smith, L. G., Hake, S., and Sylvester, A. W. (1996). The tangled-1 mutation alters cell division orientations throughout maize lead development without altering leaf shape. Development 122, 481489.

Springer, P. S., McCombie, W. R., Sundaresan, V., and Martienssen, R. A. (1995). Gene trap tagging of PROLIFERA, an essential MCM2-3-5-like gene in Arabidopsis. Science 268, 877-880.

Steeves, T. A., and Sussex, I. M. (1989). "Patterns in Plant Development." Cambridge Univ. Press, Cambridge, UK.

Strigini, M., and Cohen, S. M. (1997). A Hedgehog activity gradient contributes to AP axial patterning of the Drosophila wing. Development 124, 4697-4705.

Suthanthiran, M., Anderson, M. E., Sharma, V. K., and Meister, A. (1990). Glutathione regulates activation-dependent DNA synthesis in highly purified normal human $\mathrm{T}$ lymphocytes stimulated via the CD2 and CD3 antigens. Proc. Natl. Acad. Sci. USA 87, 3343-3347.

Tanimoto, M., Roberts, K., and Dolan, L. (1995). Ethylene is a positive regulator of root hair development in Arabidopsis thaliana. Plant J. 8, 943-948. 
Torres-Ruiz, R. A., and Jürgens, G. (1994). Mutations in the FASS gene uncouple pattern formation and morphogenesis in Arabidopsis development. Development 120, 2967-2978.

Torres-Ruiz, R. A., Lohner, A., and Jürgens, G. (1996). The GURKE gene is required for normal organisation of the apical region in the Arabidopsis embryo. Plant J. 10, 1005-1016.

Traas, J., Bellini, C., Nacry, P., Kronenberger, J., Bouchez, D., and Caboche, M. (1995). Normal differentiation patterns in plants lacking microtubular preprophase bands. Nature 375, 676-677.

Ulmasov, T., Hagen, G., and Guilfoyle, T. J. (1997). ARF1, a transcription factor that binds to auxin response elements. Science 276, 1865-1868.

van den Berg, C., Willemsen, V., Hage, W., Weisbeek, P., and Scheres, B. (1995). Cell fate in the Arabidopsis root meristem determined by directional signalling. Nature 378, 62-65.

van den Berg, C., Willemsen, V., Hendriks, G., Weisbeek, P., and Scheres, B. (1997). Short-range control of cell differentiation in the Arabidopsis root meristem. Nature 390, 287-289.

Vernon, D., and Meinke, D. (1994). Embryogenic transformation of the suspensor in $t$ win, a polyembryonic mutant of Arabidopsis. Dev. Biol. 165, 566-573.

Vollbrecht, E., Veit, B., Sinha, N., and Hake, S. (1991). The developmental gene Knotted-1 is a member of a maize homeobox gene family. Nature 350, 241-243.

Vroemen, C., Langeveld, S., Mayer, U., Ripper, G., Jürgens, G., Van Kammen, A., and de Vries, S. (1996). Pattern formation in the Arabidopsis embryo revealed by position-specific lipid transfer protein gene expression. Plant Cell 8, 783-791.

Wada, T., Tachibana, T., Shimura, Y., and Okada, K. (1997). Epidermal cell differentiation in Arabidopsis determined by a $M y b$ homolog, CPC. Science 277, 1113-1116.

Weigel, D. (1998). From floral induction to floral shape. Curr. Opin. Plant Biol. 1, 55-59.

Weigel, D., and Meyerowitz, E. M. (1994). The ABCs of floral homeotic genes. Cell 78, 203-209.

Weigmann, K., Cohen, S. M., and Lehner, C. F. (1997). Cell cycle progression, growth and patterning in imaginal discs despite inhibition of cell division after inactivation of Drosophila Cdc2 kinase. Development 124, 3555-3563.

Willemsen, V., Wolkenfelt, H., de Vrieze, G., Weisbeek, P., and Scheres, B. (1998). The HOBBIT gene is required for formation of the root meristem in the Arabidopsis embryo. Development 125, 521-531.

Yan, Y. N., and Yan, L. Y. (1998). Asymmetric cell division. Nature 392, 775-778.

Zhang, J., and Sommerville, C. R. (1997). Suspensor-derived polyembryony caused by altered expression of valyl-tRNA-synthase in the twn2 mutant of Arabidopsis. Proc. Natl. Acad. Sci. USA 94, 7349-7355. 